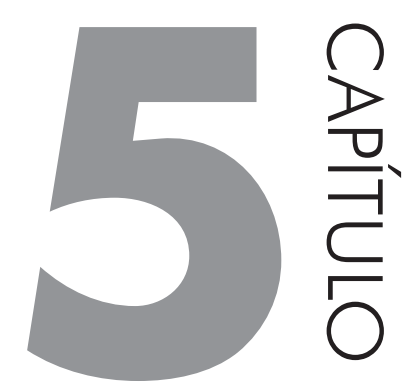

\title{
AS VOGAIS MÉDIAS PRETÔNICAS NA VARIEDADE URBANA DO PORTUGUÊS DE SÃO TOMÉ
}

\section{FABIANE DE MELLO VIANNA DA ROCHA TEIXEIRA RODRIGUES DO NASCIMENTO}

\section{INTRODUÇÃO}

Este capítulo ${ }^{1}$ descreve o vocalismo pretônico na variedade urbana do Português de São Tomé (doravante PST), investigando, dentre outros aspectos, a interferência dos processos de harmonização e de redução vocálicas, de fatores sociais e do crioulo mais falado na ilha, o Forro, na aplicabilidade da regra de elevação. Compara-se a variação atuante em São Tomé àquelas já descritas e observadas no Português Europeu (doravante PE), no Português do Brasil (doravante PB) e no Forro ou Santome, a fim de avaliar se o objeto de estudo em questão se insere em um continuum afrobrasileiro, afroeuropeu ou, ainda, se representa um sistema peculiar.

O atual panorama sociolinguístico da ilha decorre de cinco séculos de evolução, em que de língua dos colonos, o Português, paulatinamente, se transforma em língua oficial (cf. GONÇALVES; HAGEMEIJER, 2015). Ao longo de dois ciclos econômicos ocorridos na primeira e na segunda colonizações, surge um território multilíngue, em que hoje se apresentam: o Português, o Forro e três

1 Este artigo baseia-se na tese de Nascimento (2018), de onde advieram figuras e tabelas que o compõem. 
outros crioulos (o Lung'Ie, o Caboverdiano e o Angolar). Apesar de, atualmente, a República de São Tomé e Príncipe considerar a primeira como língua oficial, e utilizá-la como L1 ou L2, raros são os trabalhos que focalizam a variedade ali falada (cf. ARAÚJO, 2007; SILVEIRA, 2013). A maioria desses estudos concentra-se no nível sintático (cf. HAGEMEIJER, 2007, HAGEMEIJER; ALEXANDRE, 2012, GONÇALVES, 2010, entre outros), permanecendo obscuros seus aspectos fonético-fonológicos. A presente pesquisa colabora, portanto, para a descrição do quadro fonológico de uma das variedades do Português, além de abranger outras questões relacionadas ao funcionamento das línguas.

Para tanto, ressaltam-se, na seção 2, os sistemas vocálicos das variedades europeia (cf. seção 2.1) e brasileira da Língua Portuguesa (cf. seção 2.2) e do Forro (cf. seção 2.3), enfatizando a pauta pretônica. A seção 3 expõe os resultados das análises variacionistas, separadas pelas séries anterior e posterior. Após a descrição dos resultados, apresentam-se algumas considerações finais e as referências bibliográficas que nortearam a proposta.

\section{O VOCALISMO PRETÔNICO NO PE, NO PB E NOS CRIOULOS DO GOLFO DA GUINÉ}

\subsection{No PE}

Mateus; d'Andrade (2000) descrevem o sistema vocálico do PE, afirmando que as variedades brasileira e europeia partilham sete segmentos no contexto tônico, a saber: /i, e, $\varepsilon, a, 0, o, u /$. Para os autores, na posição pretônica, há uma diferenciação evolutiva entre elas: no $\mathrm{PB}$, o sistema reduz-se a cinco vogais e as médias são mais produtivas (cf. seção 2.2); já, no PE, elimina-se o valor opositivo dos mesmos sons e o quadro limita-se a dois graus de abertura que se manifestam em três vogais altas - [i, i, u] e uma vogal média [e], variável com [a] tônico (p[a]go $\rightarrow$ p[r]gar) (cf. MATHEUS; d' ANDRADE, 2000: 18). Depreende-se, pois, que, na última realidade, as sílabas átonas são marcadas por uma regularidade fonética maior e os quadros pré e postônicos incluem apenas quatro segmentos: $/ \mathrm{i}, \mathrm{i}, \mathrm{e}, \mathrm{u} /{ }^{2}$.

No plano fonético, as pronúncias dos 7 fonemas acentuados incluem o som [e], cujo contraste com [a] é aparente: aquele corresponde a uma "realização alternativa de outras vogais tônicas" ${ }^{3}$, precedendo i) consoantes e glide palatais $(\mathrm{t}[\mathrm{e}]$

2 Compartilham dessa visão, os estudos de Gonçalves Viana (1892), Guimarães (1927), Delgado-Martins (1975), Ploae-Hanganu (1981), Mateus; Delgado-Martins (1982), Barbosa (1988), Andrade (1996), Emiliano (2009), dentre outros.

3 Tradução de "an alternative realization of other stressed vowels". 


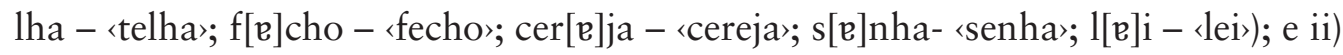
consoantes nasais (c[e]ma; $c[\mathfrak{e}] \mathrm{na} ; \mathrm{m}[\mathfrak{e}] \mathrm{nh} a)$. Palavras oriundas de bases constituídas por $[\mathrm{e}]$, $[\mathrm{e}]$ ou $[\varepsilon]$ acentuados tendem a ser concretizadas com [i] na sílaba pretônica. É o que se verifica em $\mathrm{t}[\mathrm{e}] \mathrm{lha} \rightarrow \mathrm{t}[\mathrm{i}] \mathrm{lhado} ; 1[\mathrm{e}] \mathrm{i} \rightarrow 1[\mathrm{i}] \mathrm{gal} ; \mathrm{s}[\mathrm{e}] \mathrm{lo} / \mathrm{s}[\varepsilon] \mathrm{lo}$ $\rightarrow \mathrm{s}[\mathrm{i}] \mathrm{lar}^{4}$. De modo semelhante, derivados de palavras formadas por [o] ou [0] tônicos, como "forçar" (advindo de f[o]rça / f[o]rça), se submeteriam ao alçamento da pretônica: $\mathrm{f}[\mathrm{u}] \mathrm{rçar}$. Por conseguinte, anula-se a distinção entre vocábulos como «morar> e «murar', posto que as vogais acentuadas [i] e [u] (v[i]vo e s[u]bo) não variam em contexto átono (respectivamente, v[i]ver, s[u]bir) (cf. MATEUS; D'ANDRADE, 2000: 19).

Tendo em vista a estrutura da sílaba e suas consequências no nível fonético, Mateus; d'Andrade (2000: 58) defendem a presença obrigatória de ataque ou rima, admitindo o não preenchimento de apenas uma dessas posições. Em decorrência da falta de um constituinte, algumas vogais podem não ser pronunciadas no PE, seja i) pela ausência de vogal subjacente, isto é, pelo fato de o núcleo não estar associado ao segmento ([S]cola; [ps]icologia; ca[pt]ar; [pn]eu; ri[tm]o; a[mn] ésia; a[bs]urdo; a[ft]a); ou ii) pelo apagamento de uma vogal subjacente ([pk]eno;

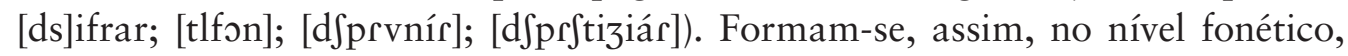
grupos consonânticos constituídos da união de: i) duas plosivas; ii) uma plosiva e uma nasal; iii) duas nasais em posição inicial ou medial de palavra; iv) uma plosiva e uma fricativa, ou vice-versa.

Os casos de apagamento de uma vogal subjacente envolvem o encontro de até três consoantes na estrutura superficial, violando o princípio da sonoridade. Deve-se pressupor a existência de vogais na estrutura subjacente, resgatadas em palavras morfologicamente relacionadas (d[e]vo, [dvér] e [dvdór]). Ademais, o ataque vazio parece bloquear as pronúncias $[\mathrm{i}]$ e $[\mathrm{u}]$, sendo muito mais prováveis ocorrências como: a) [E]lvira ("Elvira"); b) [e]/[i]lefante ("elefante"), [e]/[i] rmida (“ermida”), [e]/[i]vidente (“evidente”); e c) [o]/[0] rnar ("ornar”), [o]/[0]spital ("hospital”), $[0] /[0]$ lhar (“olhar"). Em a), a vogal aberta $[\varepsilon]$ seria proveniente da lateral em coda. Em b), os timbres médio-alto [e] e alto [i] variam; e, em c), as vogais /o/ e /o/ subjacentes não se elevam, sendo mais produtivas as pronúncias médias.

\subsection{No PB}

Câmara Jr. (1970) propõe que o número de fonemas vocálicos do PB varia de acordo com a posição do segmento quanto ao acento, atingindo seu limite

4 Nesses casos, frequentemente o segmento átono é apagado no discurso coloquial, sendo comum pronúncias como [slár] para /se'laR/. 
máximo de distinção na matriz tônica. Postula a existência, de sete unidades distintivas acentuadas que se reduzem, por neutralização, a cinco, quatro e três fonemas em ambientes pretônico, postônico não final e final, respectivamente.

Nas sílabas pretônicas, a neutralização efetiva-se entre os segmentos médios abertos e fechados, tanto na série anterior quanto na posterior. Tal fato se comprova em palavras como "pesar" e "morar", cujas pronúncias abertas ou fechadas das vogais ( $\mathrm{p}[\varepsilon]$ sar ou $\mathrm{p}[\mathrm{e}] \mathrm{sar}$ e $\mathrm{m}[\mathrm{o}]$ rar ou $\mathrm{m}[\mathrm{o}] \mathrm{rar}$, respectivamente) não implicam mudança de sentido, como ocorre em contexto tônico: são apenas variantes dos chamados arquifonemas /e/ e /o/. A maior frequência de uma ou de outra variante na fala das principais áreas geográficas do Brasil parece confirmar a distinção básica entre os dialetos do Norte e do Sul do país (cf. NASCENTES, 1953). A Tabela 1 expõe dados do Projeto ALIB - Atlas Linguístico do Brasil - a respeito de 25 capitais de estado ${ }^{5}$ e evidencia o predomínio de uma das pronúncias médias nos dialetos (cf. MOTA; CARDOSO, 2006). Nas capitais da região Nordeste, cerca de $60 \%$ das médias pretônicas são abertas. Aquelas localizadas no Norte e no Centro-Oeste ocupariam uma posição intermediária, "com maior frequência das médias abertas (36\%, no Norte, e $27,5 \%$, no Centro-Oeste) do que nas (...) do Sul e Sudeste (percentuais abaixo de 10\%), mas com menor frequência do que nas do Nordeste".

Tabela 1 Vogais médias pretônicas: resultados das capitais em Mota; Cardoso (2006: 5-6)

\begin{tabular}{|l|c|c|c|c|}
\hline \multirow{2}{*}{ REGIÕES } & \multicolumn{4}{|c|}{ VOGAIS MÉDIAS PRETÔNICAS } \\
\cline { 2 - 5 } & \multicolumn{3}{|c|}{ ABERTAS } & \multicolumn{2}{c|}{ FECHADAS } \\
\hline Norte & 1.136 & $36 \%$ & 1.008 & $\mathbf{6 4 \%}$ \\
\hline Nordeste & 1.776 & $\mathbf{6 0 , 7} \%$ & 1.683 & $\mathbf{3 9 , 3} \%$ \\
\hline Sul & 176 & $9,5 \%$ & $\mathbf{9 0 , 5} \%$ \\
\hline Sudeste & 210 & $8,6 \%$ & 2.241 & $\mathbf{9 1 , 4 \%}$ \\
\hline Centro- Oeste & 739 & $27,5 \%$ & 1.953 & $\mathbf{7 2 , 5 \%}$ \\
\hline
\end{tabular}

Os segmentos [e], [e], [o] e [o] podem, ainda, coatuar com os altos [i] e [u]. A última possibilidade, classificada como alçamento ou alteamento e facilmente verificável em todos os dialetos do PB, culmina em uma neutralização esporádica entre vogais médias e altas, conhecida como debordamento. Câmara Jr.

5 Não foram analisadas a fala de Palmas, capital do estado de Tocantins, recentemente criada, bem como a de Brasília, pelo mesmo motivo. 
(1970,1977), Bisol (1981, 2003), Callou \& Leite (2005), entre outros renomados fonólogos e foneticistas, registram ocorrências de alteamento, principalmente, em vocábulos que apresentam uma vogal alta tônica sucedendo a pretônica, em ambas as séries. A harmonia vocálica não se restringe, entretanto, a ambientes em que atua a vogal alta: por assimilação, a presença de uma vogal média alta ou média baixa e mesmo baixa na palavra favoreceria, respectivamente, a atuação dos processos de manutenção e de abertura de timbre.

Há, enfim, casos em que "as vogais se tornam articulatoriamente mais próximas dos segmentos consonantais adjacentes", compondo um contexto fonológico em que "não há, na palavra, vogal alta que possa desencadear o (...) alçamento" (CARMO, 2009: 24). Dito de outra maneira, os traços distintivos das consoantes precedente e/ou subsequente à vogal alvo, muitas vezes, inibem ou condicionam um processo. Resultados de Bisol, divulgados em Bortoni; Gomes; Malvar (1992: 14-15), indicam a maior incidência da elevação,

na presença de consoantes que tenham articulação alta: palatais e velares. Já a vogal em início de palavra, sem travamento silábico, mostrou ser ambiente refratário à elevação no dialeto carioca (cf. CALLOU; LEITE, 1986b). No caso do /o/, a elevação nesse ambiente praticamente não existe. No corpus de Callou; Leite, há registro de elevação nessa posição: [u]rigem. (...). Ainda, segundo Bisol, a consoante alveolar deverá desfavorecer a elevação.

\subsection{No Forro}

Entre as poucas pesquisas fonético-fonológicas sobre as línguas crioulas faladas nas Ilhas de São Tomé e Príncipe já divulgadas, priorizam-se as descrições de Ferraz $(1979,1987)$ e de Hagemeijer $(2009$ c) sobre o Forro, crioulo majoritário na região. Os estudos de Ferraz representam análises gerais e pioneiras que apontam aspectos fonológicos, morfológicos, sintáticos e lexicais desse (cf. FERRAZ, 1979) e de outros crioulos de base portuguesa, encontrados na Ásia e no Oeste da África (cf. FERRAZ, 1987). Aprofundando algumas observações expressas em tais abordagens, Hagemeijer (2009 c) explica o processo de aglutinação das vogais iniciais nos crioulos do Golfo da Guiné e interpreta a harmonia vocálica como uma das possíveis motivações para o fenômeno.

Segundo Ferraz (1979: 29), o Forro apresenta uma série de mecanismos, (morfológicos e fonológicos), que viabilizam a incorporação de palavras da língua de superstrato, o Português Europeu. Como os demais crioulos do Golfo da Guiné, seu sistema vocálico se constitui de 7 segmentos orais e se submete ao processo de harmonia, fenômeno recorrente nas línguas em geral, partilhado pelo Português e por outros idiomas dos grupos Banto e Kwa (cf. FERRAZ, 1979: 49). Mais precisamente, nesses crioulos, constatam-se "exemplos de um tipo de har- 
monia vocálica que é a preferência em vez da assimilação completa"' (FERRAZ, 1979: 19) (cf. Quadro 1). Trata-se de uma característica fonológica essencial, baseada em aspectos fonêmicos e morfofonêmicos: uma tendência, nem sempre sistemática, "à ocorrência da mesma vogal em duas sílabas consecutivas dentro de um morfema"7 (FERRAZ, 1979: 25).

Quadro 1 Palavras do Forro, em que se verifica o processo de harmonia vocálica, selecionadas por Ferraz (1979)

\begin{tabular}{|c|c|c|}
\hline $\begin{array}{l}\text { PALAVRA DE ORIGEM } \\
\text { (PORTUGUÊS) }\end{array}$ & $\begin{array}{l}\text { PALAVRA INCORPORADA } \\
\text { (FORRO) }\end{array}$ & TRADUÇÃO \\
\hline /‘korda/ & [ 'kodo] & "Corda" \\
\hline /‘dor/ & ['dolo] & "Dor" \\
\hline /ize'bel/o & [ze'be] & "Isabel" \\
\hline /'largu/ & ['lalugu] & "Largo" \\
\hline /'mel/ & ['mele] & "Mel" \\
\hline /'odyu/ & ['ojo] & "Ódio" \\
\hline /pə'dir/ & [pi'ji] & "Pedir" \\
\hline /'poku/ & ['poko] & "Pouco" \\
\hline /prə’sizu/ & [plišizu] & "Preciso" \\
\hline /se'ber/ & [se'be] & "Saber" \\
\hline /‘verda/ & ['vede] & "Verde" \\
\hline /vər'dadə/ & {$\left[\mathrm{v} \varepsilon^{\prime} \mathrm{d} \varepsilon\right]$} & "Verdade" \\
\hline
\end{tabular}

O acento da palavra incorporada ao crioulo corresponde àquele da forma original do Português. Nesse sentido, respeitando certas regras habituais de conversão de fonemas, a vogal do Forro, determinante para a harmonia, seria absorvida da língua de superstrato, tendendo a aproximar-se articulatoriamente dela.

6 Tradução de "In ST there are also examples of a type of vowel harmony which is preference rather than complete assimilation. Usually the preference is not completely systematic".

7 Tradução de "vowel harmony consists in a tendency for the same vowel to occur in two consecutive syllables within a morpheme". 
Hagemeijer (2009c) avalia a recorrência da aglutinação de vogais iniciais em itens etimologicamente iniciados por consoantes na língua de superstrato. Estudos mais recentes revelam que os crioulos do Golfo da Guiné partilham não só a base lexificadora, mas também, derivam da expansão no tempo e no espaço de uma protolíngua. A aglutinação de vogais iniciais no protocrioulo seria determinada pelo gênero em Português e por um reduzido sistema-ATR, aparentemente de origem edóide. O fenômeno é, assim, motivado por questões morfológicas de gênero e fonológicas de harmonia vocálica (cf. HAGEMEIJER, 2009c: 38).

Reiterando o exposto em Ferraz (1979), Hagemeijer (2009) afirma que os crioulos do Golfo da Guiné utilizam o mesmo inventário vocálico do Português padrão com 7 vogais orais [a e $\varepsilon$ i o 0 u]. Aquela tendência à mesma vogal ocorrer em duas sílabas consecutivas dentro de um morfema (cf. FERRAZ, 1979: 25) deve, todavia, ser interpretada como um caso de assimilação, pois a harmonia vocálica nos crioulos em foco é um fenômeno mais restrito ao domínio das vogais médias (cf. HAGEMEIJER, 2009c: 37). Não existem muitos trabalhos sobre as restrições fonológicas envolvidas na aglutinação de vogais iniciais, mas, no Forro são recorrentes casos como os listados no Quadro 2. Essas palavras dissilábicas indicam que, nesse sistema, i) as vogais baixa e altas não determinam a qualidade dos sons adjacentes; e ii) se manifestam restrições de coocorrência motivadas pelas vogais médias. Ao menos em itens dissilábicos, verifica-se, então, uma regra de harmonia consistente que restringe a coocorrência de segmentos médios abertos e médios fechados (cf. HAGEMEIJER, 2009c: 37).

Quadro 2 Palavras dissilábicas em Forro, extraídas de Hagemeijer (2009c: 37)

\begin{tabular}{|c|c|c|c|c|c|c|c|}
\hline $\begin{array}{ll} & V 2 \\
\text { v1 }\end{array}$ & $\mathbf{i}$ & $\mathbf{u}$ & e & $\varepsilon$ & $\mathbf{0}$ & $\mathbf{0}$ & $\mathbf{a}$ \\
\hline i & Ligi & Migu & izê (esteira, cama) & Mile & libo & Jinklo & Mina \\
\hline $\mathrm{u}$ & Buli & Mulu & Ubwê (boi) & kume & - & - & Uswa \\
\hline e & Sêji & Dêsu & Vêndê & - & - & - & Zema \\
\hline$\varepsilon$ & Peli & Petu & - & vede & - & Tebo & Bega \\
\hline 0 & Sôtxi & Wôdu & Ômê & - & pôvô & - & Lopa \\
\hline $\mathbf{0}$ & Doxi & Mosu & - & love & - & Kodo & Bola \\
\hline $\mathrm{a}$ & mali & matu & Padê & manse & kasô & Avo & Faka \\
\hline
\end{tabular}


$\mathrm{Na}$ tentativa de esclarecer a origem do processo, o autor observa alguns dados diacrônicos e alega: em um momento inicial da formação do protocrioulo do Golfo da Guiné, a "aglutinação era fortemente associada à altura da vogal"s (cf. HAGEMEIJER, 2009 c: 38). Constatava-se a seguinte relação, não absoluta, entre as vogais das palavras originais, advindas do Português Europeu, e os segmentos aglutinados na protolíngua:

Quadro 3 Aglutinação de vogais em palavras dissilábicas do Protocrioulo do Golfo da Guiné (cf. HAGEMEIJER, 2009c)

\begin{tabular}{|c|c|c|c|}
\hline VOGAIS TÔNICAS NAS & VOGAIS INICIAIS AGLUTINADAS & \multicolumn{2}{|c|}{ EXEMPLOS } \\
\hline (PE) & (PCGG) & PE & PCGG \\
\hline $\begin{array}{l}\text { Baixa e médias-baixas } \\
{\left[\begin{array}{lll}\text { \& } & \text { ol }\end{array}\right]}\end{array}$ & $\begin{array}{l}\text { Baixa e média-baixa posterior } \\
\text { [a o] }\end{array}$ & $\begin{array}{l}\text { "Pá" - ['pa] } \\
\text { "fé" - ['fe }] \\
\text { "mar" - ['mar] } \\
\text { "pé" - ['pe] } \\
\text { "nó" - ['no] }\end{array}$ & $\begin{array}{l}\text { [a]pa } \\
{[\mathrm{a}] \mathrm{fe}} \\
{[0] \mathrm{mali}} \\
{[0] \mathrm{pe}} \\
{[0] \mathrm{no}}\end{array}$ \\
\hline$\left[\begin{array}{ll}\varepsilon & \mathrm{i}\end{array}\right]$ & [o] & $\begin{array}{l}\text { "céu" - ['scw] } \\
\text { "rio" - ['řiw] }\end{array}$ & $\begin{array}{l}\text { [o]sê; } \\
\text { [o]lhô }\end{array}$ \\
\hline $\begin{array}{l}\text { Alta } \\
{[\mathrm{u}]}\end{array}$ & $\begin{array}{l}\text { Alta } \\
{[\mathrm{u}]}\end{array}$ & "nu" - ['nu] & {$[u] n u$} \\
\hline
\end{tabular}

Além da restrição fonológica, motivadora da correspondência entre a altura da vogal tônica da palavra-base e a qualidade da vogal inicial aglutinada na protolíngua, os artigos definidos de gênero feminino ("a") e masculino ("o") parecem restringir essa aglutinação às vogais baixa [a], média baixa, média alta e alta posteriores $\left[\begin{array}{lll}0 & 0 & u\end{array}\right]$. A comparação entre os sistemas decorrentes da expansão da língua-mãe no tempo e no espaço indica, entretanto, comportamentos singulares. Na tentativa de explicá-los, Hagemeijer (2009 c: 43) adverte:

Inicialmente, o protocrioulo do Golfo da Guiné era essencialmente o resultado da aquisição do Português por escravos edóides. Durante este período correspondente, em grande medida, à sociedade de habitação, houve indiscutivelmente facilidade de acesso à língua alvo (TL) e, portanto, o decalque

\footnotetext{
8 Tradução de "agglutination is strongly associated to vowel height".
} 
de gênero do Português foi também capaz de satisfazer a restrição edóide de iniciar os nomes por vogal. ${ }^{9}$

Atualmente, os crioulos falados na Ilha de São Tomé (Forro e Angolar) possuem um número considerável de palavras introduzidas por consoantes, indicando uma maior influência da língua de superstrato e a consequente baixa produtividade da aglutinação de vogais iniciais. No Forro, o fenômeno limita-se aos itens aglutinados naquele estágio diacrônico da protolíngua.

Em suma, a assimilação e a harmonia vocálicas (de altura e/ou ATR) são fenômenos comuns ao PE, PB e a todos crioulos do Golfo da Guiné (cf. HAGEMEIJER, 2009: 37) que coexistem na Ilha com o Português, sendo provável que também se manifestem na amostra investigada.

\section{ANÁLISE DOS DADOS}

A amostra geral que serve de base à presente investigação integra 11.179 ocorrências, selecionadas dos inquéritos que constituem o Projeto Variedades Africanas do Português (VAPOR), do Centro de Linguística da Universidade de Lisboa. Trata-se de 6.643 dados de /e/ e 4.536 de /o/, extraídos de Diálogos entre Informante e Documentador (DID), realizados com dezessete indivíduos, residentes na Ilha de São Tomé e distribuídos por sexo, três faixas etárias (25-35 anos; 36-55 anos; 56 anos em diante) e três níveis de escolaridade (Fundamental, Médio e Superior). Com base nas auto declarações dos entrevistados, avaliou-se, também, a frequência de uso do Forro na aplicabilidade do alçamento. Finalmente, postularam-se onze variáveis estruturais, a saber: qualidade da vogal da sílaba seguinte, nasalidade da vogal alvo, características articulatórias (pontos e modos de articulação) das consoantes dos ataques precedente e subsequente à pretônica, tipo de sílaba, distância entre a vogal alvo e outra alta presente no vocábulo, localização da pretônica na palavra e classe gramatical.

A princípio, relacionaram-se cinco variantes das médias pretônicas (alta, média-alta, média-baixa, ditongada e zero) às informações estruturais e sociais supracitadas. A baixa produtividade dos processos de abertura, de ditongação e de apagamento, nas duas amostras (cf. Tabela 2), implicou o descarte de tais

\footnotetext{
9 Tradução de "early proto-GGC is essentially the result of Edoid slaves acquiring Portuguese. Since this period corresponds by and large to the societé d'habitation, there was arguably better access to the Target Language (TL) and therefore phonetic calquing upon Portuguese gender was additionally able to satisfy the Edoid constraint that nouns are vowel-initial”.
} 
ocorrências das análises variacionistas e a sua centralização no alçamento e na manutenção do timbre médio.

Tabela 2 Variantes das vogais médias pretônicas /e/ e /o/ no PST

\begin{tabular}{|l|c|c|c|c|}
\hline \multirow{2}{*}{ VARIANTES } & \multicolumn{2}{|c|}{ /e/ } & \multicolumn{2}{c|}{ /o/ } \\
\cline { 2 - 5 } & oco. & $\%$ & oco. & $\%$ \\
\hline$[\mathrm{i} \mathrm{u}]$ & 3.371 & 50.8 & 2.193 & 48.3 \\
\hline$[\mathrm{e} \mathrm{o}]$ & 2.544 & 38.3 & 1.736 & 38.3 \\
\hline$[\varepsilon$ o] & $\mathbf{6 8}$ & $\mathbf{1}$ & $\mathbf{2 7}$ & $\mathbf{0 . 6}$ \\
\hline [ej oj] & $\mathbf{2 6 6}$ & $\mathbf{4}$ & $\mathbf{5 5 8}$ & $\mathbf{1 2 . 3}$ \\
\hline [ ] & $\mathbf{3 9 4}$ & $\mathbf{5 . 9}$ & $\mathbf{2 2}$ & $\mathbf{0 . 5}$ \\
\hline Total de ocorrências & 6.643 & 59.4 & 4.536 & 40.6 \\
\hline
\end{tabular}

Eliminaram-se, também, os casos pouco produtivos e semicategóricos/categóricos e modificou-se a configuração inicial de determinados grupos de fatores. Após as alterações, a elevação foi estabelecida como valor de aplicação e os dados expostos a rodadas no GoldVarb X.

\subsection{A pretônica /e/}

Reiterando o exposto acima, 59.4\% da amostra geral, ou seja, 6.643 dados referem-se à vogal /e/. Concentrar a investigação nas pronúncias [i] e [e] reduziu o número inicial a 5.915 casos, distribuídos por variante conforme a Tabela 3.

Tabela 3 Distribuição das ocorrências de alçamento e manutenção da vogal /e/

\begin{tabular}{|c|c|c|}
\hline VARIANTES & OCO. & $\%$ \\
\hline$[\mathrm{i}]$ & 3.371 & 57 \\
\hline$[\mathrm{e}]$ & 2.544 & 43 \\
\hline
\end{tabular}

Postularam-se as hipóteses de maior incidência da pronúncia alta quando a vogal está no início de palavra: i) em sílabas desprovidas de ataque e de coda; ii) naquelas, cuja posição de ataque está disponível e a coda é preenchida por /S/ ou /N/; e iii) na sequência /deS/ (prefixal ou não). Além desses ambientes, cogitou-se a maior probabilidade de elevação nas vogais inseridas em contextos de hiato; e 
nos itens "depois", “pessoa(s)" e "pessoal”. Como se verifica na Tabela 4, só no contexto de hiato, a hipótese inicial não se confirmou:

Tabela 4 Distribuição das ocorrências de [e] e de [i], no PST, em alguns contextos aparentemente mais suscetíveis à elevação

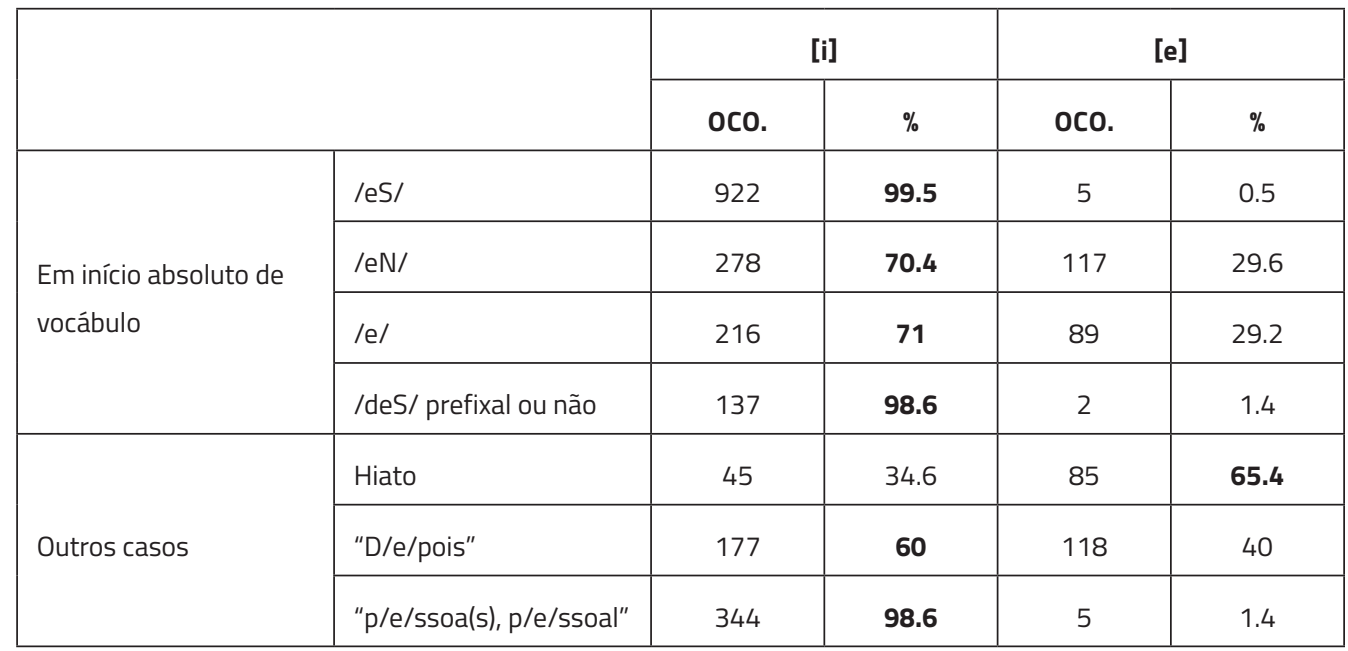

Além de haver menos registros de advérbios, numerais e conjunções com a vogal /e/, neles o alçamento se destacou. Uma análise qualitativa dos resultados comprova, contudo, a interferência da repetição de certos itens. Além dessas ocorrências, desprezaram-se, por comportamento semicategórico/categórico em favor da pronúncia [i], os itens isolados "pessoa(s)", "pessoal" e "depois". A amostra final avaliou, então, 3.334 ocorrências de vogal média não recuada, distribuídas entre as variantes [i] e [e] do seguinte modo:

Tabela 5 Redistribuição das ocorrências de alçamento e manutenção da vogal /e/

\begin{tabular}{|c|c|c|}
\hline PRETÔNICA ANTERIOR & OCO. & $\%$ \\
\hline$[\mathrm{i}]$ & 1.216 & 36.5 \\
\hline$[\mathrm{e}]$ & 2.118 & 63.5 \\
\hline
\end{tabular}

A rodada eleita como mais coerente estabeleceu algumas variáveis como influentes na elevação de /e/. Cada uma delas será descrita nas subseções adiante, comparando-se, sempre que possível, os resultados aqui obtidos àqueles divulgados por Rocha (2013), relativos a dados contemporâneos do PB. Por ora, o Quadro 4 destaca esses condicionamentos em uma escala decrescente de relevância, bem como a significância e o input da regra na variedade urbana do Português de São Tomé. 
Quadro 4 Rodada selecionada para a elevação de /e/

\begin{tabular}{|l|}
\hline \multicolumn{1}{|c|}{ ELEVAÇÃo DA PRETÔNICA /e/ } \\
\hline Qualidade da vogal da sillaba seguinte \\
Modo de articulação da consoante precedente \\
Modo de articulação da consoante do ataque da sillaba seguinte \\
Ponto de articulação da consoante do ataque da silaba seguinte \\
Distância entre a vogal alvo e outra alta presente no vocábulo \\
Classe gramatical do vocábulo \\
Grau de escolaridade dos Informantes \\
Natureza da atonicidade \\
Faixa etária dos informantes \\
Sexo dos informantes \\
Frequência de uso do Forro \\
Input: .42
\end{tabular}

a) Qualidade da vogal da sílaba seguinte

$\mathrm{O}$ condicionamento mais determinante para o alteamento de /e/ na amostra investigada é a qualidade da vogal da sílaba contígua à pretônica, cujos fatores cogitados e seus respectivos índices distribuem-se conforme a Tabela 6:

Tabela 6 Atuação da variável Tipo de vogal contígua para o alçamento de /e/, no PST

\begin{tabular}{|l|l|c|c|c|}
\hline \multirow{2}{*}{ VARIÁVEL TIPO DE VOGAL CONTíGUA } & \multicolumn{3}{c|}{ [i] } \\
\cline { 3 - 5 } & Altas (homorgânica e não homorgânica) & $550 / 1.088$ & $\mathbf{5 1}$ & $\mathbf{. 5 5}$ \\
\cline { 2 - 5 } & Médias-altas & $457 / 1.290$ & $\mathbf{3 5}$ & $\mathbf{. 5 4}$ \\
\cline { 2 - 5 } $\begin{array}{l}\text { Vogal tônica/ătona } \\
\text { (oral/nasal/ nasalizada) }\end{array}$ & Baixas (médias-baixas e baixa) & $209 / 956$ & 22 & .39 \\
\hline
\end{tabular}

A princípio, cogitou-se a influência das diferentes alturas da vogal contígua e, ainda, da homorganicidade e da não homorganicidade das altas, na manifestação do alçamento da pretônica /e/. No entanto, a constatação de comportamentos semelhantes permitiu redistribuí-las em três graus de abertura: altas (homorgânicas e não homorgânicas), médias-altas e baixas (médias-baixas e baixa). Embora com pesos relativos muito próximos da neutralidade (P. R.: .50), a pronúncia [i] é mais provável, se na sílaba contígua há uma vogal alta (homorgânica ou não) (P. R.: .55) ou vogais médias altas (P. R.: .54). Por outro lado, a contiguidade com segmentos baixos favorece a manutenção de timbre em /e/ (P. R.: .39). 
Em Rocha (2013), a qualidade da vogal contígua também foi selecionada como o fator mais influente na elevação da média anterior. Como ilustra a Tabela 7, a autora considera aspectos mais específicos nesta variável. As peculiaridades entre as investigações não impedem, contudo, que se estabeleçam comparações. Nas duas realidades, as altas se destacam, sendo comprovada a elevação da média pretônica por harmonização com o traço alto da vogal contígua em Nova Iguaçu e em São Tomé.

Tabela 7 Atuação da variável Tipo de vogal contígua para o alçamento de /e/, em Nova Iguaçu (cf. ROCHA, 2013: 111)

\begin{tabular}{|l|l|c|c|c|}
\hline \multirow{2}{*}{ VARIÁVEL TIPO DE VOGAL CONTíGUA } & \multicolumn{3}{c|}{ [i] } \\
\cline { 2 - 5 } & Alta homorgânica & OCO. & $\%$ & P. R. \\
\cline { 2 - 5 } & Alta não homorgânica & $87 / 172$ & $\mathbf{5 1}$ &. $\mathbf{. 7 3}$ \\
\cline { 2 - 5 } $\begin{array}{l}\text { Vogal tônica } \\
\text { (oral/nasal/nasalizada) }\end{array}$ & Não altas & $196 / 3.543$ & 5 & .29 \\
\hline \multirow{3}{*}{$\begin{array}{l}\text { Vogal átona } \\
\text { (oral/nasal/nasalizada) }\end{array}$} & Alta homorgânica & $104 / 550$ & 19 &. $\mathbf{8 1}$ \\
\cline { 2 - 5 } & Alta não homorgânica & $29 / 184$ & 16 & .74 \\
\cline { 2 - 5 } & Não altas & $70 / 882$ & 8 & .31 \\
\hline
\end{tabular}

\section{b) Modo de articulação da consoante precedente}

O segundo fator mais influente na elevação de /e/ diz respeito ao processo de redução vocálica e foi cogitado na intenção de avaliar a relação entre algumas consoantes e o processo de alçamento, isto é, de verificar a ocorrência de assimilação entre consoantes e vogais nas amostras.

Tabela 8 Atuação da variável Modo de articulação da consoante precedente para o alçamento de /e/, no PST

\begin{tabular}{|l|c|c|c|}
\hline \multicolumn{1}{c|}{$\begin{array}{c}\text { VARIÁvEL MODO DE ARTICULAÇÃo } \\
\text { (CONTEXTO PRECEDENTE) }\end{array}$} & Oco. & $\%$ & P. R. \\
\cline { 2 - 4 } & [i] & .49 \\
\hline Oclusivas & $335 / 1.001$ & 33.5 & .66 \\
\hline Fricativas & $498 / 1.017$ & 49 & .33 \\
\hline Líquidas & $208 / 855$ & 24 & .47 \\
\hline Nasais & $168 / 448$ & 37.5 & \\
\hline
\end{tabular}


Como aponta a Tabela 8, na análise final, esta variável considerou apenas os dados de segmentos oclusivos, fricativos, nasais e líquidos (laterais e vibrantes), pois os casos de ataque vazio se tornaram escassos à proporção que se descartaram as ocorrências em início absoluto com coda vazia ou preenchida por /S/ ou /N/.

Todos os índices percentuais dos contextos preservados, confirmam a menor incidência da elevação. Já os pesos relativos indicam que, quando /e/ atua como núcleo de sílabas com ataque preenchido por consoantes fricativas, a pronúncia [i] é mais provável (P. R.: .66); e que a manutenção se destaca sucedendo líquidas (P. R.: .33). Por outro lado, segmentos oclusivos (P. R.: .49) e nasais (P. R.: .47) apresentaram índices muito próximos da neutralidade, mesmo mais favoráveis à manutenção.

Se comparados os corpora contemporâneos de São Tomé e de Nova Iguaçu, verifica-se que os dois estudos descartam os casos de ataque vazio, em virtude de a maioria das ocorrências se referir às sequências /e/, /eN/ e /eS/ em início de vocábulo. No $\mathrm{PB}$, o primeiro contexto (/e/) seria mais suscetível à manutenção e a elevação mais provável nos outros dois (/eN/ e /eS/) (cf. BRANDÃO et al., 2012). Já na fala urbana de São Tomé, além das sequências /eN/ e /eS/, sílabas leves desprovidas de ataque tendem ao alçamento, sendo, portanto, a pronúncia [i] mais frequente nos três ambientes.

No que concerne aos demais modos de articulação precedentes, há peculiaridades entre as duas amostras. Todos os percentuais indicam o predomínio de [e]. No primeiro estudo, consoantes nasais $(20 \%$, P. R.: .53) e líquidas $(14 \%$, P. R.: .53) se mostraram, contudo, mais suscetíveis à elevação, em contraste com as oclusivas (9\%, P. R.: .49) e fricativas (12\%, P. R.: .48). Já neste, segmentos fricativos (49\%, P. R.: .66) estão mais sujeitos ao alçamento do que líquidos $(24 \%$, P. R.: .33), oclusivos (33.5\%, P. R.: .49) e nasais (37.5\%, P. R.: .47).

c) Modo de articulação da consoante do ataque da sílaba seguinte

No que se refere ao modo de articulação da consoante que ocupa o ataque da sílaba subsequente à vogal alvo, os dados de [i] se distribuem conforme a Tabela 9:

Tabela 9 Atuação da variável Modo de articulação da consoante do ataque subsequente para o alçamento de /e/, no PST

\begin{tabular}{|l|c|c|c|}
\hline \multicolumn{1}{c|}{$\begin{array}{c}\text { VARIÁVEL MODO DE ARTICULAÇÃo } \\
\text { (ATAQUE SUBSEQUENTE) }\end{array}$} & OCO. & $\%$ & P. R. \\
\cline { 2 - 5 } & $426 / 1.335$ & 32 & .42 \\
\hline Oclusivas & $120 / 251$ & 48 & $\mathbf{. 5 6}$ \\
\hline Nasais & $489 / 1.145$ & 43 & $\mathbf{. 5 8}$ \\
\hline Fricativas & $95 / 194$ & 49 & $\mathbf{. 5 4}$ \\
\hline Laterais & & & \\
\hline
\end{tabular}


Todos os percentuais acima remetem à maior incidência da manutenção, porém os pesos relativos indicam que a presença de fricativas (P. R.: .58), nasais (P. R.: .56) e laterais (P. R.: .54), respectivamente, no início da sílaba que sucede a pretônica contribuem para sua elevação, ao passo que a pronúncia [e] é mais provável quando a mesma posição é preenchida por oclusivas (P. R.: .42).

A Tabela 10 compara os resultados de Rocha (2013) aos aqui expostos para a mesma variável:

Tabela 10 Atuação da variável Modo de articulação da consoante do ataque subsequente para o alçamento de /e/, em Nova Iguaçu (cf. ROCHA, 2013: 113) e no PST

\begin{tabular}{|c|c|c|c|c|c|c|}
\hline \multirow{3}{*}{$\begin{array}{l}\text { VARIÁVEL MODO DE ARTICULAÇÃO } \\
\text { (ATAQUE SUBSEQUENTE) }\end{array}$} & \multicolumn{6}{|c|}{ [i] } \\
\hline & \multicolumn{3}{|c|}{ NOVA IGUAÇU/RJ } & \multicolumn{3}{|c|}{ SÃO TOMÉ } \\
\hline & oco. & $\%$ & P. R. & oco. & $\%$ & P. R. \\
\hline Oclusivas & $242 / 1.795$ & 13 & .73 & $426 / 1.335$ & 32 & .42 \\
\hline Fricativas & $277 / 2.475$ & 11 & .38 & 489/1.145 & 43 & .58 \\
\hline Líquidas & $97 / 1.165$ & 8 & .27 & - & - & - \\
\hline Nasais & $221 / 551$ & 40 & .71 & $120 / 251$ & 48 & .56 \\
\hline Laterais & - & - & - & $95 / 194$ & 49 & .54 \\
\hline
\end{tabular}

Há certa correspondência entre as duas variedades, pois, nas duas amostras, consoantes nasais subsequentes à pretônica favorecem a realização alta $(40 \%$, P. R.: .71 em Nova Iguaçu; e 48\%, P. R.: .56 em São Tomé). Ao mesmo tempo, se, naquele estudo, oclusivas apresentam percentual de [i] superior $(13 \%)$ ao de fricativas $(11 \%)$; neste, o contrário se verifica, tendo os segmentos fricativos índices maiores $(43 \%)$ do que oclusivos $(32 \%)$.

d) Ponto de articulação da consoante do ataque da sílaba seguinte

O quarto contexto de provável elevação da pretônica anterior é o ponto de articulação da consoante do ataque subsequente. Esta variável foi modificada, reorganizando-se de acordo com as variantes expressas na Tabela 11 e todos os percentuais comprovam a maior aplicabilidade da regra de manutenção. Quanto aos pesos relativos, ambos se aproximam da neutralidade. No entanto, precedendo consoantes [+coronais], a tendência à pronúncia [i] é maior (P. R.: .52). Vale destacar, ainda, a discrepância entre os dados de cada um dos contextos em evidência, já que segmentos [+coronais] (2.092) são mais numerosos na amostra, se comparados aos [-coronais] (1.141). 
Tabela 11 Atuação da variável Ponto de articulação da consoante do ataque subsequente para o alçamento de /e/, no PST

\begin{tabular}{|l|c|c|c|}
\hline \multirow{2}{*}{$\begin{array}{c}\text { VARIÁVEL PONTO DE ARTICULAÇÃO } \\
\text { (ATAQUE SUBSEQUENTE) }\end{array}$} & \multicolumn{3}{c|}{ [i] } \\
\cline { 2 - 4 } & 0CO. & $\%$ & P. R. \\
\hline [+ Coronais] (alveolares e alveopalatais) & $743 / 2.092$ & 35.5 & $\mathbf{. 5 2}$ \\
\hline [-coronais] (labiais e velares) & $383 / 1.141$ & 33.5 & .47 \\
\hline
\end{tabular}

Rocha (2013) também assinala esta variável como influente nos processos de manutenção e de alçamento da vogal média anterior em Nova Iguaçu e descreve resultados semelhantes, mesmo postulando fatores distintos. Como ilustra a Tabela 12, naquela análise, as consoantes do ataque subsequente se distribuem em [+coronais, + anteriores], [+coronais, -anteriores] e [-coronais]. Ressaltam-se, contudo, percentuais de elevação i) superiores no segundo grupo (18\%); e ii) idênticos, quando a vogal /e/ precede segmentos [+coronais, +anteriores] e [-coronais] (15\%).

Tabela 12 Atuação da variável Ponto de articulação da consoante do ataque subsequente para o alçamento de /e/, em Nova Iguaçu (cf. ROCHA, 2013: 119)

\begin{tabular}{|l|c|c|c|}
\hline \multirow{2}{*}{$\begin{array}{c}\text { VARIÁVEL PONTO DE ARTICULAÇÃo } \\
\text { (ATAQUE SUBSEQUENTE) }\end{array}$} & \multicolumn{3}{c|}{ [i] } \\
\cline { 2 - 4 } & 0CO. & $\%$ & P. R. \\
\hline [+ Coronais, + anteriores] (alveolares) & $548 / 3.703$ & 15 & $\mathbf{. 5 6}$ \\
\hline [+ Coronais, -anteriores] (Alveopalatais e palatais) & $70 / 384$ & $\mathbf{1 8}$ & $\mathbf{. 5 6}$ \\
\hline [-Coronais] (labiais e velares) & $328 / 2.125$ & 15 & .37 \\
\hline
\end{tabular}

e) Distância entre a vogal alvo e outra alta presente no vocábulo

A distância entre a vogal alvo e outra alta presente na palavra foi o quinto aspecto relevante para o alçamento de /e/ na variedade urbana do PST. Compõem o grupo, o número de sílabas entre o segmento alvo e outro alto acentuado ou não.

Trata-se de uma variável que dialoga com a qualidade da vogal da sílaba seguinte, ressaltando o acento como fator relevante: a pronúncia [i] é mais recorrente em presença de um segmento alto tônico e contíguo (P. R.: .64). Em contrapartida, i) quando há altas átonas, não contíguas (P. R.: .22) e contíguas (P. R.: .38), a manutenção é mais frequente; e ii) tônicas não contíguas aproximam-se da neutralidade (P. R.: .41), mesmo tendendo à manutenção. 
Tabela 13 Atuação da variável Distância de outra vogal alta na palavra para o alçamento de /e/, no PST

\begin{tabular}{|c|c|c|c|c|}
\hline \multirow{2}{*}{\multicolumn{2}{|c|}{ VARIÁVEL DISTÂNCIA DE OUTRA VOGAL ALTA }} & \multicolumn{3}{|c|}{ [i] } \\
\hline & & oco. & $\%$ & P. R. \\
\hline \multirow{2}{*}{ Tônica } & Contígua & $400 / 675$ & 59 & .64 \\
\hline & Não contígua & $55 / 161$ & 34 & .41 \\
\hline \multirow{2}{*}{ Átona } & Contígua & $150 / 418$ & 36 & .38 \\
\hline & Não contígua & $26 / 98$ & 26.5 & .22 \\
\hline
\end{tabular}

f) Classe gramatical dos vocábulos

O sexto fator selecionado como favorável à elevação de /e/ foi a classe gramatical dos vocábulos de cuja estrutura a pretônica faz parte. A variável foi submetida a uma série de alterações durante a investigação, sendo preservados, na abordagem variacionista, apenas os fatores apontados na Tabela 14:

Tabela 14 Atuação da variável Classe de vocábulos para o alçamento de /e/, no PST

\begin{tabular}{|l|c|c|c|}
\hline \multirow{2}{*}{\multicolumn{1}{c|}{ VARIÁVEL CLASSES DE VOCÁBULOS }} & \multicolumn{3}{c|}{ [i] } \\
\cline { 2 - 4 } & oco. & $\%$ & P. R. \\
\hline Substantivos & $410 / 1.276$ & 32 & .48 \\
\hline Adjetivos & $149 / 494$ & 30 & .44 \\
\hline Verbos: formas finitas & $180 / 564$ & 32 & .51 \\
\hline Verbos: formas não finitas & $317 / 740$ & 43 & .56 \\
\hline
\end{tabular}

Como se verifica, todos os percentuais sugerem a maior incidência da pronúncia [e] na amostra com pesos relativos mais próximos da neutralidade. A elevação é, todavia, mais provável nos verbos, sobretudo em suas formas não finitas (P. R.: .56). Em contrapartida, adjetivos (P. R.: .44) e substantivos (P. R.: .48) estão mais sujeitos à retenção do timbre médio na série anterior.

\section{g) Grau de escolaridade dos informantes}

As quatro variáveis extralinguísticas consideradas nesta investigação, a saber: grau de escolaridade, faixa etária, sexo dos informantes e frequência de uso do Forro, foram selecionadas pela análise estatística, correspondendo, nessa 
ordem, às sétima, nona, décima e décima primeira variáveis influentes no alçamento de /e/. O nível de escolaridade foi postulado na tentativa de avaliar o prestígio das pronúncias média-alta e alta no dialeto em pauta. Como é possível depreender da Tabela 15, todos os pesos relativos se aproximam da neutralidade (P. R.: .50), mas em informantes com nível superior, a pronúncia [i] é mais provável (P. R.: .56), aqueles com nível médio tendem à manutenção (P. R.: .44) e os de nível Fundamental são neutros (P. R.: .50).

Tabela 15 Atuação da variável Escolaridade dos informantes para o alçamento de /e/, no PST

\begin{tabular}{|l|c|c|c|}
\hline \multirow{2}{*}{\multicolumn{1}{|c|}{ VARIÁVEL ESCOLARIDADE DOS INFORMANTES }} & \multicolumn{2}{c|}{ [i] } \\
\cline { 2 - 4 } & 0co. & $\%$ & P. R. \\
\hline Fundamental - 5 a 8 anos de escolaridade & $252 / 818$ & 31 & .50 \\
\hline Médio - 9 a 11 anos de escolaridade & $405 / 1.212$ & 33.5 & .44 \\
\hline Superior - mais de 11 anos de escolaridade & $559 / 1.304$ & 43 & $\mathbf{. 5 6}$ \\
\hline
\end{tabular}

\section{b) Natureza da atonicidade}

A oitava variável selecionada como determinante para a aplicabilidade da regra de elevação em /e/ foi a natureza da atonicidade da vogal alvo. A variável foi explorada, a fim de observar se, na amostra investigada, a pronúncia [i] é mais frequente quando integra o núcleo de sílabas sempre átonas nas diferentes formas de um mesmo paradigma (cf. BISOL, 1981: 82). Os índices percentuais descritos na Tabela 16 revelam a baixa produtividade do alçamento nos dois tipos de vogal átona considerados (36\% para eventuais e $37 \%$ para permanentes). No entanto, corroborando a perspectiva de Bisol (1981) sobre o PB, na fala urbana do Português de São Tomé, a pronúncia [i] é mais provável em sílabas sempre átonas (P. R.: .59).

Tabela 16 Atuação da variável Natureza da atonicidade da vogal alvo para o alçamento de /e/, no PST

\begin{tabular}{|l|c|c|c|}
\hline \multirow{2}{*}{\multicolumn{1}{|c|}{ VARIÁVEL NATUREZA DA ATONICIDADE DE /EI }} & \multicolumn{3}{c|}{ [i] } \\
\cline { 2 - 4 } & OCO. & $\%$ & P. R. \\
\hline Átona eventual & $870 / 2.400$ & 36 & .46 \\
\hline Átona permanente & $346 / 934$ & 37 & .59 \\
\hline
\end{tabular}




\section{i) Faixa etária dos informantes}

A faixa etária dos informantes foi também selecionada como motivação da pronúncia [i] na amostra. À semelhança de outras pesquisas de cunho variacionista, foi postulada para averiguar se há indícios de mudança ou se a flutuação fonética entre manutenção e alçamento nesta realidade linguística permanece estável. Sobre sua interferência na aplicabilidade da regra de elevação em Nova Iguaçu, Rocha (2013: 121) adverte:

os percentuais e ocorrências (...) evidenciam a maior frequência da retenção do timbre médio (...), independentemente da geração, já que, em todas as faixas etárias ressaltadas, essa pronúncia supera os $80 \%$. Os pesos relativos indicam, contudo, que indivíduos mais jovens são mais resistentes à mudança sonora de /e/ (.46), ao passo que os de meia idade e idosos igualmente se mostraram mais suscetíveis à sua aplicação (.52).

$\mathrm{Na}$ Tabela 17, apontam-se os índices registrados para a mesma variável na fala urbana do Português de São Tomé. Como se verifica, os percentuais e ocorrências descritos comprovam a maior incidência de [e] e, indicando um cenário de variação estável, todos os pesos relativos se aproximam da neutralidade, mesmo revelando a maior resistência de indivíduos mais velhos (P. R.: .46) e mais jovens (P. R.: .49) à elevação, enquanto que na faixa intermediária o processo seria mais provável (P. R.: .54).

Tabela 17 Atuação da variável Faixa etária dos informantes para o alçamento de /e/, no PST

\begin{tabular}{|c|c|c|c|}
\hline \multirow{2}{*}{ VARIÁVEL FAIXA ETÁRIA } & \multicolumn{3}{|c|}{ [i] } \\
\hline & oco. & $\%$ & P. R. \\
\hline $25-35$ anos & $502 / 1.359$ & 37 & .49 \\
\hline $36-55$ anos & $446 / 1.107$ & 40.5 & .54 \\
\hline 56 anos em diante & $268 / 868$ & 31 & .46 \\
\hline
\end{tabular}

j) Sexo dos Informantes

O sexo dos informantes foi a penúltima variável selecionada como relevante para o alçamento de /e/ na amostra. A variável foi inserida entre as demais informações extralinguísticas dos entrevistados, com o fito de constatar se a vogal pretônica varia na fala de homens e de mulheres no dialeto em pauta. Estudos sociolinguísticos costumam incluí-la no perfil dos informantes, salientando que, de acordo com a avaliação social da variante, a mudança sonora é mais provável em homens do que em mulheres. Ressaltam, entretanto, a maior adequação da 
fala feminina à norma de prestígio. Na variedade urbana do Português de São Tomé, a variante alta se mostrou pouco produtiva em ambos os sexos, com percentuais inferiores a $40 \%$, sendo mais representativa em homens.

Tabela 18 Atuação da variável Sexo dos informantes para o alçamento de /e/, no PST

\begin{tabular}{|c|c|c|c|}
\hline \multirow{2}{*}{ VARIÁVEL SEXO DOS INFORMANTES } & \multicolumn{3}{|c|}{ [i] } \\
\hline & oco. & $\%$ & P. R. \\
\hline Masculino & $805 / 2.144$ & 37.5 & .53 \\
\hline Feminino & 411/1.190 & 34.5 & .44 \\
\hline
\end{tabular}

Em consonância com os índices percentuais e de ocorrências, os pesos relativos expressos na Tabela 18 indicam, assim, que a variante [i] é mais frequente no discurso masculino (P. R.: .53) do que no feminino (P. R.: .44).

\section{k) Frequência de uso do Forro}

A última variável selecionada como influente na elevação de /e/ no corpus em destaque foi a frequência de uso do Forro. Reconhece-se o multilinguismo como inerente à realidade santomense e a presente variável foi inserida nas análises na tentativa de investigar a interferência do contato entre o sistema autóctone mais falado na região e o Português. Tendo em vista os relatos dos entrevistados, consideram-se, três diferentes graus de emprego do crioulo:

Tabela 19 Atuação da variável Frequência de uso do Forro para o alçamento de /e/, no PST

\begin{tabular}{|l|c|c|c|}
\hline \multirow{2}{*}{\multicolumn{2}{|c|}{ VARIÁVEL FREQUÊNCIA DE USO DO FORRO }} & \multicolumn{3}{|c|}{ [i] } \\
\cline { 2 - 4 } & Oco. & $\%$ & P. R. \\
\hline Pouca ou nenhuma & $590 / 1.536$ & 38.5 & .50 \\
\hline Média & $572 / 1.559$ & 36.5 & .53 \\
\hline Alta & $54 / 239$ & 22.5 & .34 \\
\hline
\end{tabular}

A comparação entre os valores expressos na Tabela 19 revela que a maioria das ocorrências concentra-se entre indivíduos que declararam pouca/nenhuma e média frequência do Forro em seu cotidiano. Apenas um dos dezessete entrevistados declarou alta frequência, o que justifica a menor produtividade do alçamento nesse quesito (P. R.: .34). Vale ressaltar, por fim, que, embora as duas outras possibilidades se aproximem da neutralidade, indivíduos cujo contato 
com o Forro é mediano estão mais propensos à elevação da pretônica anterior (P. R.: .53).

\subsection{A pretônica /o/}

A pretônica /o/ está representada em cerca de $40 \%$ (4.536 dados) da amostra geral. A Tabela 20 retoma o exposto no início deste capítulo, enfatizando as cinco variantes pelas quais se distribuem os dados da série em pauta, representativas, respectivamente, dos processos de alçamento, manutenção, abaixamento, ditongação e apagamento:

Tabela 20 Distribuição das ocorrências pelas variantes de /o/, no PST

\begin{tabular}{|c|c|c|}
\hline VARIANTES & oco. & $\%$ \\
\hline$[u]$ & 2.193 & 48.3 \\
\hline$[0]$ & 1.736 & 38.3 \\
\hline$[$ ] $]$ & 27 & 0.6 \\
\hline$[0 w]$ & 558 & 12.3 \\
\hline$[$ ] & 22 & 0.5 \\
\hline
\end{tabular}

As variantes baixa, ditongada e zero foram pouco produtivas. Por isso, optou-se por centralizar a análise final nos dois primeiros processos. A restrição reduziu o corpus a 3.929 dados, cerca de $56 \%$ de [o] e $44 \%$ de [u].

Tabela 21 Distribuição das ocorrências pelas variantes média fechada e alta de /o/, no PST

\begin{tabular}{|c|c|c|}
\hline VARIANTE & oco. & $\%$ \\
\hline$[\mathrm{u}]$ & 2.193 & 55.8 \\
\hline$[0]$ & 1.736 & 44.2 \\
\hline
\end{tabular}

A observação mais específica da variável Tipo de sílaba demostrou que, descartados os dados de abertura, de ditongação e de apagamento, os contextos de travamento por /l/, /N/ e /S/ foram pouco produtivos. As ocorrências de sílabas sem travamento em contexto de hiato são, de igual modo, reduzidas. Nelas, a elevação é, todavia, recorrente, assim como nos casos de coda preenchida por /R/. 
Tabela 22 Distribuição das ocorrências de manutenção e de alçamento de /o/, por tipo de sílaba, no PST

\begin{tabular}{|l|c|c|c|c|}
\hline \multirow{2}{*}{ VARIÁVEL TIPO DE SÍLABA } & \multicolumn{2}{|c|}{ [u] } & \multicolumn{2}{c|}{ [o] } \\
\cline { 2 - 5 } & oco. & $\%$ & 0co. & $\%$ \\
\hline Travada por /S/ & 77 & 64.2 & 43 & 35.8 \\
\hline Travada por /N/ & 41 & 23.3 & 135 & 76.7 \\
\hline Travada por /R/ & 794 & 72.8 & 297 & 27.2 \\
\hline Travada por /I/ & 5 & 15.2 & 28 & 84.8 \\
\hline Sem travamento & 1.177 & 49.4 & 1.207 & 50.6 \\
\hline Sem travamento em contexto de hiato & 98 & 82.4 & 21 & 17.6 \\
\hline
\end{tabular}

Como ilustra a Tabela 23, a alta frequência dos itens lexicais "porque" (517/793) e "portanto" (123/793) parece interferir nos resultados do último grupo. Em tais vocábulos, em "bocado(s), bocadinho" e em "Tomé, tomense(s)", a pronúncia [u] é frequente, ao passo que em "você", [o] se destaca. Os poucos dados de "comigo/consigo" variam entre as duas pronúncias.

Tabela 23 Distribuição das ocorrências de elevação e manutenção de timbre, de acordo com o item analisado no PST

\begin{tabular}{|l|c|c|c|c|}
\hline \multirow{2}{*}{ ITEM LEXICAL } & \multicolumn{2}{|c|}{ [u] } & \multicolumn{2}{c|}{ [o] } \\
\cline { 2 - 5 } & oco. & $\%$ & 0co. & \% \\
\hline "Porque" & 511 & $\mathbf{9 9}$ & 6 & 1 \\
\hline "Portanto" & 122 & $\mathbf{9 9}$ & 1 & 1 \\
\hline "Bocado(s), bocadinho" & 80 & $\mathbf{1 0 0}$ & 0 & 0 \\
\hline "Tomé, tomense(s)" & 199 & $\mathbf{9 3}$ & 14 & 7 \\
\hline "Comigo, consigo" & 7 & $\mathbf{4 4}$ & 9 & $\mathbf{5 6}$ \\
\hline "Você" & 4 & 12 & 30 & $\mathbf{8 8}$ \\
\hline
\end{tabular}

As palavras supracitadas foram desconsideradas na abordagem variacionista, para que o condicionamento lexical não interferisse nos resultados. As eliminações reduziram os dados de conectores, numerais e advérbios (em geral e em -mente) a poucos itens lexicais e ocorrências de manutenção e de alçamen- 
to. Optou-se, portanto, por desconsiderá-los, limitando a última amostra a 2.693 ocorrências de vogal média recuada, distribuídas conforme a Tabela 24:

Tabela 24 Distribuição das ocorrências de vogal /o/ por variante considerada no PST

\begin{tabular}{|c|c|c|}
\hline PRETÔNICA POSTERIOR & OCO. & $\%$ \\
\hline$[\mathrm{u}]$ & 1.144 & 42.5 \\
\hline$[0]$ & 1.549 & 57.5 \\
\hline
\end{tabular}

No Quadro 5, listam-se as motivações do alçamento da pretônica /o/, com base na rodada selecionada para a descrição dos resultados. Em consonância com o efetuado para o tratamento de /e/, adiante comenta-se, por ordem de relevância, cada uma das variáveis apontadas.

Quadro 5 Rodada selecionada para /o/

\begin{tabular}{|l|}
\hline \multicolumn{1}{|c|}{ PRETÔNICA /o/ } \\
\hline Modo de articulação da consoante precedente \\
Distância entre a vogal alvo e outra alta presente no vocábulo \\
Grau de escolaridade dos informantes \\
Qualidade da vogal da silaba seguinte \\
Modo de articulação da consoante do ataque da sillaba seguinte \\
Nasalidade da vogal alvo \\
Classe gramatical do vocábulo \\
Frequência de uso do Forro \\
Sexo dos informantes \\
Ponto de articulação da consoante precedente \\
Faixa etária dos informantes \\
\hline Input: .33
\end{tabular}

a) Modo de articulação da consoante precedente

O modo de articulação da consoante precedente foi o primeiro fator selecionado como relevante para a elevação de /o/ na variedade urbana do Português de São Tomé.

Trata-se de uma das variáveis que remete ao processo de redução vocálica e que visa a estabelecer relações de assimilação entre traços vocálicos e consonantais. Os casos de vogal precedida por consoantes laterais e vibrantes foram poucos e apresentam comportamentos muito semelhantes no que tange à distribuição 
das variantes média e alta, justificando seu agrupamento em um único fator: as consoantes líquidas. À exceção das oclusivas que correspondem ao maior número de ocorrências (1.467) e tendem à elevação (55\% e P. R.: .61), todos os índices apontados na Tabela 25 comprovam a manutenção de /o/ como regra no dialeto, independentemente do contexto precedente, com pesos .31, .33 e .39, respectivamente, em presença de segmentos fricativos, nasais e líquidos.

Tabela 25 Atuação da variável Modo de articulação da consoante precedente para o alçamento de /o/, no PST

\begin{tabular}{|l|c|c|c|}
\hline \multicolumn{1}{c|}{$\begin{array}{c}\text { [u] } \\
\text { (CONIÁVEL MODO DE ARTICULAÇÃo }\end{array}$} & \multicolumn{3}{c|}{} \\
\cline { 2 - 4 } & 0co. & $\%$ & P. R. \\
\hline Oclusivas & $806 / 1.467$ & 55 & .61 \\
\hline Fricativas & $88 / 329$ & 27 & .31 \\
\hline Líquidas (laterais e vibrantes) & $154 / 462$ & 33 & .39 \\
\hline Nasais & $81 / 276$ & 29 & .33 \\
\hline
\end{tabular}

Em Rocha (2013), a variável em questão foi também selecionada como influente na elevação de /o/. Apesar de os percentuais comprovarem a manutenção como regra no dialeto (cf. Tabela 26), à semelhança da amostra em evidência, "na fala de Nova Iguaçu, consoantes oclusivas (28.3\%) (...) foram menos resistentes” (p. 125) ao alteamento. A comparação entre os índices expressos adiante confirma a importância de tais sons para a incidência da variante [u], tanto no Português do Brasil quanto no Português de São Tomé. Em contrapartida, sucedendo líquidas e nasais, a vogal em questão parece ser mais resistente à elevação, nas duas variedades.

Tabela 26 Atuação da variável Modo de articulação da consoante precedente para o alçamento de /o/, em Nova Iguaçu (cf. ROCHA, 2013: 125) e no PST

\begin{tabular}{|l|c|c|c|c|c|c|}
\hline \multirow{2}{*}{$\begin{array}{c}\text { VARIÁVEL MODO DE ARTICULAÇÃo } \\
\text { (CONTEXTO PRECEDENTE) }\end{array}$} & \multicolumn{3}{|c|}{ [u] } \\
\cline { 2 - 8 } & NOVA IGUAÇU/RJ & \multicolumn{3}{c|}{ SÃo TOMÉ } \\
\cline { 2 - 8 } & OCO. & $\%$ & P. R. & 0CO. & $\%$ & P. R. \\
\hline Oclusivas & $724 / 2.559$ & 28 & .64 & $806 / 1.467$ & 55 & .61 \\
\hline Fricativas & $87 / 553$ & 16 & .57 & $88 / 329$ & 27 & .31 \\
\hline Líquidas (laterais e vibrantes) & $22 / 740$ & 3 & .13 & $154 / 462$ & 33 & .39 \\
\hline Nasais & $41 / 396$ & 10 & .38 & $81 / 276$ & 29 & .33 \\
\hline
\end{tabular}


b) Distância entre a vogal alvo e outra alta presente no vocábulo

O segundo fator influente para o alçamento de /o/ na amostra em pauta foi a distância entre a pretônica alvo e uma vogal alta tônica ou átona presente no vocábulo. Trata-se de uma variável que dialoga com a qualidade da vogal contígua, na avaliação da atuação do processo de harmonia vocálica, demonstrando que, quando na sílaba subsequente à média posterior há um segmento alto tônico, a pronúncia $[\mathrm{u}]$ é mais provável (P. R.: .72).

Tabela 27 Atuação da variável Distância entre a pretônica e outra vogal alta na palavra para o alçamento de /o/, no PST

\begin{tabular}{|c|c|c|c|c|}
\hline \multirow{2}{*}{\multicolumn{2}{|c|}{ VARIÁVEL DISTÂNCIA DE OUTRA VOGAL ALTA }} & \multicolumn{3}{|c|}{ [u] } \\
\hline & & oco. & $\%$ & P. R. \\
\hline \multirow{2}{*}{ Tônica } & Contígua & $252 / 369$ & 68 & .72 \\
\hline & Não contígua & $52 / 170$ & 30.5 & .50 \\
\hline \multirow{2}{*}{ Átona } & Contígua & $278 / 764$ & 36.5 & .40 \\
\hline & Não contígua & 28/109 & 26 & .43 \\
\hline
\end{tabular}

Embora os pesos relativos das demais variantes dessa variável se aproximem da neutralidade, dividir a palavra com uma vogal alta átona contígua (P. R.: .40) ou não contígua (P. R.: .43) suscita a retenção do timbre médio, ao passo que tônicas não contíguas se mostraram neutras (P. R.: .50).

Tendo em vista a fala de Nova Iguaçu, os índices expressos na Tabela 28 ilustram comportamentos semelhantes aos descritos. Naquela pesquisa, a presença de uma vogal alta tônica contígua à média posterior se destaca como principal contexto de elevação $(58 \%$, P. R.: .59).

Tabela 28 Atuação da variável Distância entre a pretônica e outra vogal alta na palavra para o alçamento de /o/, em Nova Iguaçu (cf. ROCHA, 2013: 129)

\begin{tabular}{|c|c|c|c|c|}
\hline \multirow{2}{*}{\multicolumn{2}{|c|}{ VARIÁVEL DISTÂNCIA DE OUTRA VOGAL ALTA }} & \multicolumn{3}{|c|}{ [u] } \\
\hline & & \multirow{2}{*}{$\begin{array}{c}\text { oco. } \\
369 / 631\end{array}$} & \multirow{2}{*}{$\begin{array}{c}\% \\
58\end{array}$} & \multirow{2}{*}{$\begin{array}{r}\text { P. R. } \\
.59\end{array}$} \\
\hline \multirow{2}{*}{ Tônica } & Contígua & & & \\
\hline & Não contígua & 21/189 & 11 & .37 \\
\hline \multirow{2}{*}{ Átona } & Contígua & $92 / 674$ & 14 & .50 \\
\hline & Não contígua & $5 / 89$ & 6 & 18 \\
\hline
\end{tabular}


c) Grau de escolaridade dos informantes

O nível de escolaridade dos informantes foi a terceira variável destacada como relevante para a manifestação da pronúncia [u] no PST. Grosso modo, estudos sobre a elevação das vogais médias em diferentes variedades do Português comprovam que a retenção do timbre médio é mais frequente na maior parte dos dialetos do PB e que pronúncias altas se destacam no PE, independentemente da formação intelectual dos entrevistados. A variedade urbana do Português de São Tomé parece refletir a norma padrão europeia, sendo a frequência da variante $[\mathrm{u}]$ diretamente proporcional aos anos de formação dos informantes.

Tabela 29 Atuação da variável Escolaridade dos informantes para o alçamento de /o/, no PST

\begin{tabular}{|l|c|c|c|}
\hline \multirow{2}{*}{\multicolumn{1}{|c|}{ VARIÁVEL ESCOLARIDADE DOS INFORMANTES }} & \multicolumn{2}{c|}{ [u] } \\
\cline { 2 - 4 } & 0CO. & $\%$ & P. R. \\
\hline Fundamental - 5 a 8 anos de escolaridade & $277 / 754$ & 36 & .42 \\
\hline Médio - 9 a 11 anos de escolaridade & $330 / 887$ & 37 & .44 \\
\hline Superior - mais de 11 anos de escolaridade & $537 / 1.052$ & 51 &. $\mathbf{. 6 0}$ \\
\hline
\end{tabular}

Dito de outra forma, indivíduos com formação básica (P. R.: .42) e média (P. R.: .44) são mais resistentes à aplicabilidade da regra e, nos mais escolarizados, a tendência à pronúncia $[\mathrm{u}]$ é maior (P. R.: .60). É notório salientar que as ocorrências foram extraídas de diálogos entre um documentador e um informante. Neles, os entrevistados sabem que estão sendo gravados, apesar de ignorarem os propósitos reais das entrevistas. Trata-se de um contexto razoavelmente monitorado em que a tendência ao alçamento é menor em informantes menos cultos do que naqueles mais escolarizados.

A comparação entre os pesos relativos constatados nesta investigação e aqueles descritos em Rocha (2013) (cf. Tabela 30) sugere a existência de normas padrão distintas nas variedades brasileira e santomense da Língua Portuguesa, ao menos no tocante ao alçamento da média recuada. A variedade brasileira costuma atribuir à pronúncia [o] certo prestígio. Por conseguinte, os percentuais de elevação seriam inversamente proporcionais à escolaridade dos informantes, isto é, maior naqueles menos escolarizados (25\%) e menor naqueles com maior formação (17\%). Em contrapartida, na variedade urbana do Português de São Tomé, cuja norma de referência é o Português Europeu, o oposto parece se apresentar. 
Tabela 30 Atuação da variável Escolaridade dos informantes para o alçamento de /o/, em Nova Iguaçu (cf. ROCHA, 2013: 131) e no PST

\begin{tabular}{|c|c|c|c|c|c|c|}
\hline \multirow{3}{*}{$\begin{array}{c}\text { VARIÁVEL ESCOLARIDADE } \\
\text { DOS INFORMANTES }\end{array}$} & \multicolumn{6}{|c|}{ [u] } \\
\hline & \multicolumn{3}{|c|}{ NOVA IGUAÇU/RJ } & \multicolumn{3}{|c|}{ SÃO TOMÉ } \\
\hline & oco. & $\%$ & P. R. & oco. & $\%$ & P. R. \\
\hline Nivel Fundamental & $356 / 1.430$ & 25 & .58 & $277 / 754$ & 36 & .42 \\
\hline Nível Médio & $225 / 1.148$ & 20 & .49 & $330 / 887$ & 37 & .44 \\
\hline Nível Superior & $293 / 1.670$ & 17 & .44 & $537 / 1.052$ & 51 & .60 \\
\hline
\end{tabular}

d) Qualidade da vogal da sílaba seguinte

A qualidade da vogal da sílaba subsequente foi a quarta variável mais determinante para o alçamento da média posterior. Nessa variável, as ocorrências se distribuem conforme a altura da vogal contígua e vogais altas, sobretudo a não homorgânica (P. R.: .68), favorecem a elevação. Ao mesmo tempo, segmentos baixos (P. R.: .36) e médio-altos (P. R.: .44) inibem a regra, sendo a manutenção mais atuante, precedendo-os.

Tabela 31 Atuação da variável Tipo de vogal contígua para o alçamento de /o/, no PST

\begin{tabular}{|l|l|c|c|c|}
\hline \multicolumn{2}{|c|}{ VARIÁVEL TIPO DE VOGAL CONTígUA } & \multicolumn{3}{c|}{ [u] } \\
\cline { 3 - 5 } & Alta homorgânica & oco. & $\%$ & P. R. \\
\hline \multirow{3}{*}{$\begin{array}{l}\text { Vogal tônica/átona } \\
\text { (oral/nasal/nasalizada) }\end{array}$} & Alta não homorgânica & $180 / 423$ & 42.5 & .54 \\
\cline { 2 - 5 } & Médias-altas & $381 / 766$ & 50 & .68 \\
\cline { 2 - 5 } & Baixas (médias-baixas e baixa) & $263 / 779$ & 34 & .44 \\
\hline
\end{tabular}

Além de distribuir os dados de Nova Iguaçu pelos diferentes traços de altura das vogais, Rocha (2013) avalia a influência de segmentos tônicos e átonos e, com base nos índices reproduzidos na Tabela 32, afirma:

embora a vogal [u] acentuada também favoreça a aplicação da regra (.57), os pesos relativos e índices percentuais corroboram a defesa de que [i] seja mais influente no alçamento da pretônica em ambas as séries, já que o alçamento de /o/ também é mais provável em contextos em que, sucedendo a vogal alvo, se encontra a tônica alta não homorgânica (.91) ou um segmento 
átono equivalente (.62). Em contrapartida, a manutenção de timbre é mais provável se, após a vogal átona, existe uma tônica não alta, já que o menor peso lhe foi atribuído, quando o fator de referência é o alçamento (ROCHA, 2013: 124).

Tabela 32 Atuação da variável Tipo de vogal contígua para o alçamento de /o/, em Nova Iguaçu (cf. ROCHA, 2013: 124)

\begin{tabular}{|l|l|c|c|c|}
\hline \multicolumn{2}{|c|}{ VARIÁVEL TIPO DE VOGAL CONTíGUA } & \multicolumn{3}{c|}{ [u] } \\
\cline { 2 - 5 } & Alta homorgânica & OCo. & $\%$ & P. R. \\
\cline { 2 - 5 } & Alta não homorgânica & $348 / 521$ & $\mathbf{6 7}$ & .91 \\
\cline { 2 - 5 } $\begin{array}{l}\text { Vogal tônica } \\
\text { (oral/nasal/nasalizada) }\end{array}$ & $\begin{array}{l}\text { Não alta (média baixa, média } \\
\text { alta e baixa) }\end{array}$ & $240 / 1.992$ & 12 & .37 \\
\hline \multirow{3}{*}{$\begin{array}{l}\text { Vogal átona } \\
\text { (oral/nasal/nasalizada) }\end{array}$} & Alta homorgânica & $27 / 309$ & 9 & .43 \\
\cline { 2 - 5 } & Alta não homorgânica & $72 / 390$ & 18 & .62 \\
\cline { 2 - 5 } & $\begin{array}{l}\text { Não alta (média baixa, média } \\
\text { alta e baixa) }\end{array}$ & $160 / 903$ & 18 & .51 \\
\hline
\end{tabular}

Constata-se, desse modo, a atuação do processo de harmonização vocálica, nas duas amostras e em ambas as séries, sendo os traços de altura assimilados na elevação e na retenção das médias.

\section{e) Modo de articulação da consoante do ataque da sílaba seguinte}

A fim de analisar a atuação da redução vocálica na amostra, a influência do modo de articulação do segmento introdutório da sílaba subsequente à vogal /o/ foi considerada. A variável se associa aos pontos de articulação precedente e do ataque subsequente à vogal alvo e ao modo de articulação da consoante do ataque da sílaba de núcleo pretônico. Se, na mesma sílaba, segmentos líquidos puderam ser agrupados por apresentarem comportamentos similares, nesta variável, oclusivas e nasais passaram a integrar um mesmo grupo de fatores e manteve-se a distinção entre ele e os demais modos previamente estabelecidos.

Oclusivas e nasais predominaram na amostra, mas, juntamente com as fricativas, se aproximam da neutralidade (P. R.: .51 e .52, respectivamente) quando o fator de referência é a elevação de /o/. A pronúncia [u] é tendência precedendo laterais (P. R.: .56) e a manutenção é mais provável antecedendo vibrantes (P. R.: .23). 
Tabela 33 Atuação da variável Modo de articulação da consoante do ataque subsequente para o alçamento de /o/, no PST

\begin{tabular}{|l|c|c|c|}
\hline \multicolumn{1}{c|}{$\begin{array}{c}\text { VARIÁVEL MODO DE ARTICULAÇÃo } \\
\text { (ATAQUE SUBSEQUENTE) }\end{array}$} & \multicolumn{3}{c|}{ [u] } \\
\cline { 2 - 4 } & OCO. & $\%$ & P. R. \\
\hline Oclusivas e nasais & $759 / 1.760$ & 43 & .51 \\
\hline Fricativas & $220 / 551$ & 40 & .52 \\
\hline Laterais & $130 / 220$ & 59 & .56 \\
\hline Vibrantes & $34 / 153$ & 22 & .23 \\
\hline
\end{tabular}

Em Nova Iguaçu, Rocha (2013: 126) descreve motivações distintas no tocante à atuação da mesma variável. Naquele dialeto, "os maiores índices de elevação correspondem, respectivamente, a segmentos nasais (P. R.: .63 e 37\%) e fricativos (P. R.: .55 e 20\%). Em contrapartida, a manutenção é mais frequente, em presença de segmentos líquidos (P. R.: .41 e 19\%) e oclusivos (P. R.: .43 e $11 \%$ )".

\section{f) Nasalidade da vogal alvo}

A nasalidade foi a sexta variável influente na pronúncia [u]. Descartadas as ocorrências de ditongação, os dados de vogal dita nasal se limitaram a 176 ocorrências, apresentando-se em 135 delas (77\%) a variante [o]. O contexto foi descartado e a análise final concentrou-se nas vogais orais e nasalizadas.

Tabela 34 Atuação da variável Nasalidade da vogal alvo para o alçamento de /o/, no PST

\begin{tabular}{|l|c|c|c|}
\hline \multirow{2}{*}{ VARIÁveL NASALIDADE DA VOGAL PRETÔNICA } & \multicolumn{3}{c|}{ [u] } \\
\cline { 2 - 5 } & OCO. & $\%$ & P. R. \\
\hline Oral & $818 / 1.983$ & 41.5 & .49 \\
\hline Nasalizada & $285 / 529$ & 54 &. $\mathbf{5 4}$ \\
\hline
\end{tabular}

Como ilustram os valores expressos na Tabela 34, os pesos relativos se aproximam da neutralidade. No entanto, em vogais nasalizadas, há um número menor de ocorrências e uma maior tendência à elevação (P. R.: .54), e nas orais o oposto se verifica (P. R.: .49).

A Tabela 35 compara os índices percentuais e de ocorrências supracitados àqueles apresentados por Rocha (2013) e revela similaridades entre os resulta- 
dos das duas análises, ilustrativas das variedades brasileira e santomense do Português.

Tabela 35 Atuação da variável Nasalidade da vogal alvo para o alçamento de /o/, em Nova Iguaçu (cf. ROCHA, 2013: 136) e no PST

\begin{tabular}{|l|c|c|c|c|c|c|}
\hline \multirow{2}{*}{\begin{tabular}{c}
\multirow{2}{*}{$\begin{array}{c}\text { VARIÁVEL NASALIDADE DA VOGAL } \\
\text { PRETONICA }\end{array}$} \\
\cline { 2 - 8 }
\end{tabular}} & \multicolumn{4}{|c|}{ NOVA IGUAÇU/RJ } & \multicolumn{3}{c|}{ SÃO TOMÉ } \\
\cline { 2 - 8 } Oral & OCO. & $\%$ & P. R. & 0CO. & $\%$ & P. R. \\
\hline Nasal & $601 / 3.176$ & 19 & .51 & $818 / 1.983$ & 41.5 & .49 \\
\hline Nasalizada & $90 / 635$ & 14 & .35 & - & - & - \\
\hline
\end{tabular}

Considerando não só segmentos orais e nasalizados, mas também os ditos nasais, Rocha (2013: 135) salienta:

Em contraste com o verificado em /e/, a baixíssima produtividade da variante [u] em contextos de travamento nasal reitera o defendido em Câmara Jr, (1970), Callou; Leite (1986), Battisti (1993), dentre outros que constam da Bibliografia deste estudo. No entanto, não anula a relevância da nasalidade sobre o alçamento, já que os pesos relativos sugerem vogais nasalizadas (.62) como mais suscetíveis à elevação, enquanto segmentos orais se aproximam consideravelmente da neutralidade.

\section{g) Classe gramatical do vocábulo}

A classe gramatical do vocábulo de que a pretônica faz parte foi o sétimo grupo relevante para a implementação de $[\mathrm{u}]$ no dialeto investigado. A variável incluía substantivos, adjetivos, formas finitas e não finitas dos verbos, conectores, numerais, advérbios (em geral e em -mente), formas em -(z)inho (a), pronomes oblíquos "comigo" e "consigo" e, de modo mais específico, os itens "porque", "portanto", "bocado(s), bocadinho", "Tomé, tomense(s) e "você". Como se esclareceu no início desta seção, por apresentarem comportamentos (semi)categóricos em favor de uma das variantes, todos os itens isolados foram descartados. Ao mesmo tempo, os demais conectores, numerais, advérbios, palavras terminadas em -(z)inho e os pronomes "comigo" e "consigo" foram ínfimos na amostra, justificando a concentração dos dados nas quatro primeiras classes supracitadas. Ademais, por apresentarem comportamentos semelhantes, os dados de adjetivos e formas finitas dos verbos foram reunidos em um único fator, que se contrapôs, na análise final, aos substantivos e formas não finitas dos verbos. 
Tabela 36 Atuação da variável Classe de vocábulos para o alçamento de /o/, no PST

\begin{tabular}{|l|c|c|c|}
\hline \multirow{2}{*}{\multicolumn{1}{c|}{ VARIÁVEL CLASSES DE VOCÁBULOS }} & \multicolumn{3}{c|}{ [u] } \\
\cline { 2 - 4 } & oco. & $\%$ & P. R. \\
\hline Substantivos & $554 / 1.225$ & 45 & .55 \\
\hline Adjetivos e formas finitas dos verbos & $323 / 851$ & 38 & .46 \\
\hline Verbos formas não finitas & $233 / 509$ & 46 & .43 \\
\hline
\end{tabular}

Em todas as classes listadas, os percentuais apontam o predomínio da manutenção do timbre médio e pesos relativos muito próximos da neutralidade. É evidente, entretanto, que grande parte dos itens em que a vogal média posterior atua são substantivos, o que parece favorecer a maior probabilidade de elevação nesse grupo (P. R.: .55), em contraste com as formas não finitas (P. R.: .43) e finitas dos verbos e os adjetivos (P. R.: .46), que se mostraram mais resistentes à aplicabilidade da regra.

\section{b) Frequência de uso do Forro}

A frequência de uso do Forro se mostrou influente na aplicabilidade da regra de elevação em /o/. Como se enfatizou no tratamento da média anterior, a variável considera três possibilidades de frequência, tendo em vista as auto declarações dos entrevistados. Ela foi postulada na intenção de observar se as variantes das médias pretônicas refletem, de algum modo, o contato entre o crioulo mais falado na região em destaque e o Português.

Tabela 37 Atuação da variável Frequência de uso do Forro para o alçamento de /o/, no PST

\begin{tabular}{|l|c|c|c|}
\hline \multirow{2}{*}{\multicolumn{1}{|c|}{ VARIÁVEL FREQUÊNCIA DE USO DO FORRO }} & \multicolumn{3}{c|}{ [u] } \\
\cline { 2 - 4 } & OCO. & $\%$ & P. R. \\
\hline Pouca ou nenhuma & $613 / 1.254$ & 49 & .56 \\
\hline Média & $472 / 1.222$ & 38.5 & .47 \\
\hline Alta & $59 / 217$ & 27 & .35 \\
\hline
\end{tabular}

Grande parte das ocorrências distribui-se entre os indivíduos que alegam pouco/nenhum e médio contato com Forro. À medida que somente um dos dezessete informantes se insere no último grupo, é natural que essa realidade seja menos produtiva, limitando-se a 217 ocorrências, em que a manutenção é mais provável (P. R.: .35). Apesar de os índices relativos às demais possibilidades se 
aproximarem da neutralidade, em informantes cujo contato com o Forro é menor ou nulo, a pronúncia [u] é mais provável (P. R.: .56), enquanto a tendência à manutenção se destaca naqueles cuja frequência é intermediária (P. R.: .47).

\section{i) Sexo dos informantes}

A variável sexo foi apontada pelo Goldvarb X como a nona variável relevante para a aplicabilidade da regra de elevação da média recuada. Estudos variacionistas costumam inseri-la entre as características sociais investigadas sob a alegação de que, de acordo com o valor social atribuído a uma variante, a probabilidade de mudança sonora é maior em homens do que em mulheres, pois elas tenderiam a se adequar com mais facilidade à norma de prestígio. Os percentuais inseridos na Tabela 38 demonstram a maior incidência da manutenção de /o/ em ambos os sexos. No entanto, na fala feminina, a tendência à elevação é maior (P. R.: .56).

Tabela 38 Atuação da variável Sexo dos informantes para o alçamento de /o/, no PST

\begin{tabular}{|l|c|c|c|}
\hline \multirow{2}{*}{\multicolumn{2}{|c|}{ SEXO DOS INFORMANTES }} & \multicolumn{3}{c|}{ [u] } \\
\cline { 2 - 4 } & 0co. & $\%$ & P. R. \\
\hline Masculino & $660 / 1.620$ & 41 & .46 \\
\hline Feminino & $484 / 1.073$ & 45 & .56 \\
\hline
\end{tabular}

Segundo Rocha (2013: 134), em Nova Iguaçu, o oposto se verifica: "mesmo sendo evidente a baixíssima produtividade da variante alta em ambos os sexos (...), o alçamento foi mais frequente no discurso de informantes do sexo masculino $(22.4 \%)$, sendo esse fator mais sujeito à aplicação da regra $(.54)$ ".

Tabela 39 Atuação da variável Sexo dos informantes para o alçamento de /o/, em Nova Iguaçu (cf. ROCHA, 2013: 135) e no PST

\begin{tabular}{|l|c|c|c|c|c|c|}
\hline \multirow{2}{*}{\begin{tabular}{c}
\multirow{2}{*}{$\begin{array}{c}\text { VARIÁVEL SEXO } \\
\text { DOS INFORMANTES }\end{array}$} \\
\cline { 2 - 8 }
\end{tabular}} & \multicolumn{3}{|c|}{ NOVA IGUAÇU/RJ } \\
\cline { 2 - 8 } & OCO. & $\%$ & P. R. & 0CO. & $\%$ & P. R. \\
\hline Masculino & $450 / 2.011$ & $\mathbf{2 2}$ & $\mathbf{. 5 4}$ & $660 / 1.620$ & 41 & .46 \\
\hline Feminino & $424 / 2.237$ & 19 & .46 & $484 / 1.073$ & $\mathbf{4 5}$ & $\mathbf{. 5 6}$ \\
\hline
\end{tabular}

O confronto entre as duas investigações sugere que a pronúncia média é mais prestigiada do que a alta na fala de Nova Iguaçu e na variedade urbana do Portu- 
guês de São Tomé, a variante [u] se destaca, sendo, talvez, a manutenção mais estigmatizada.

\section{j) Ponto de articulação da consoante precedente}

Dialogando com outras abordagens sobre a relação entre os processos de redução vocálica e de elevação de /o/, esta investigação considerou também, os pontos de articulação dos segmentos adjacentes ao núcleo pretônico, sendo o ponto de articulação da consoante do ataque precedente à vogal alvo selecionada como variável influente na realização alta. Como aponta a tabela a seguir, o condicionamento se limitou aos pontos labial, alveolar e velar, já que, em virtude da pouca produtividade, descartaram-se os casos de ataque preenchido por alveopalatais e palatais:

Tabela 40 Atuação da variável Ponto de articulação da consoante precedente para o alçamento de /o/, no PST

\begin{tabular}{|c|c|c|c|}
\hline \multirow{2}{*}{$\begin{array}{l}\text { VARIÁVEL PONTO DE ARTICULAÇÃO } \\
\text { (CONTEXTO PRECEDENTE) }\end{array}$} & \multicolumn{3}{|c|}{ [u] } \\
\hline & oco. & $\%$ & P. R. \\
\hline Labiais & $387 / 854$ & 45.5 & .52 \\
\hline Alveolares & 274/791 & 34.5 & .44 \\
\hline Velares & $450 / 822$ & 55 & .54 \\
\hline
\end{tabular}

Mais uma vez, os pesos relativos expressos na Tabela 40 aproximam-se da neutralidade. Velares (P. R.: .54) e labiais (P. R.: .52) estão, entretanto, mais propensos à elevação do que alveolares (P. R.: .44).

$\mathrm{Na}$ tentativa de observar a influência do ponto de articulação da consoante que precede a vogal /o/ em Nova Iguaçu, Rocha (2013) distribui as ocorrências em [+ coronais] (alveolares, alveopalatais e palatais) e [-coronais] (labiais e velares). Em meio às peculiaridades de cada investigação, as duas abordagens revelam comportamentos semelhantes no que diz respeito à atuação dessa variável, pois em Rocha (2013: 132), “vogais posteriores precedidas por consoantes [-coronais] se destacaram (...) como o ambiente mais favorável à aplicação da regra (.55), (...) ao passo que segmentos [+coronais] precedendo a vogal alvo parecem motivar sua preservação como média [o]".

l) Faixa etária dos informantes

A faixa etária dos informantes foi a última variável importante para a pronúncia $[u]$ na amostra. Em conformidade com outros estudos variacionistas, ela 
foi cogitada na tentativa de atestar indícios de uma mudança em andamento ou de estabilidade entre os processos de alçamento e de manutenção na realidade linguística em pauta.

A Tabela 41 descreve os resultados encontrados na variedade urbana do Português de São Tomé. À semelhança do verificado em /e/, todos os percentuais e ocorrências revelam a maior representatividade da manutenção, com pesos relativos muito próximos da neutralidade. Em indivíduos de meia idade (P. R.: .46), todavia, a manutenção é mais provável, enquanto naqueles com idade superior a 56 anos, a pronúncia $[\mathrm{u}]$ se destaca (P. R.: .55) e os mais jovens se mostraram neutros (P. R.: .50).

Tabela 41 Atuação da variável Faixa etária dos informantes para o alçamento de /o/, no PST

\begin{tabular}{|l|c|c|c|}
\hline \multirow{2}{*}{\multicolumn{1}{c|}{ VARIÁveL FAIXA ETÁRIA }} & \multicolumn{3}{c|}{ [u] } \\
\cline { 2 - 4 } & 0Co. & $\%$ & P. R. \\
\hline $25-35$ anos & $422 / 1.001$ & 42 & .50 \\
\hline $36-55$ anos & $364 / 884$ & 41 & .46 \\
\hline $\mathbf{5 6}$ anos em diante & $358 / 804$ & 44.5 & .55 \\
\hline
\end{tabular}

\section{CONSIDERAÇÕES FINAIS}

Em linhas gerais, a investigação da aplicabilidade da regra de elevação de /e/ e de /o/ aponta baixos índices (input .42 para a média anterior e .33 para a média recuada), demonstrando uma maior tendência à manutenção do timbre médio na fala de São Tomé. Grande parte dos condicionamentos selecionados para a implementação da regra se aproxima da neutralidade e, à medida que a recorrência de um mesmo item se mostrou influente em determinados resultados, acredita-se na interferência do léxico e da coatuação de motivações nos corpora pesquisados.

Cumpre ressaltar o fato de as amostras investigadas unirem ocorrências submetidas ao alçamento por harmonização e por redução vocálicas, o que pode justificar a seleção de uma quantidade superior de variáveis e a sobreposição de gatilhos. No que remete ao primeiro fenômeno, as pronúncias [i] e [u] sobressaem, quando i) na sílaba subsequente à pretônica, há uma vogal alta acentuada [i] (P. R.: .64) e [u] (P. R.: .72)]; vogais altas (acentuadas ou não) sucedem a pretônica anterior (P. R.: .55) e a vogal [i] é contígua à posterior (P. R.: .68). Constituem indícios da atuação do fenômeno de redução a maior incidência da pronúncia [i], i) antes de consoantes fricativas (P. R.: .58), nasais (P. R.: .56), laterais (P. R.: .54) e [+coronais] (P. R.: .52); ou depois de fricativas (P. R.: .66). Na série recuada, a 
elevação é mais provável, se a vogal é i) precedida por oclusivas (P. R.: .61), velares (P. R.: .54) e labiais (P. R.: .52); ou sucedida por um ataque preenchido por laterais (P. R.: .56), fricativas (P. R.: .52) e oclusivas e nasais (P. R.: .51). Talvez, a observação isolada de cada processo auxilie o esclarecimento das verdadeiras motivações e dos inputs de cada um deles, mas o tempo previsto para o desenvolvimento desta pesquisa não permitiu apurar a questão.

Mesmo constatando a maior influência de motivações estruturais, não se desprezaram os perfis sociais dos entrevistados e o seu contato com o crioulo majoritário na região. As quatro variáveis extralinguísticas foram selecionadas como influentes na elevação de /e/ e de /o/. A fim de comparar sua atuação nas duas amostras, reiteram-se, nas Tabelas 42, 43, 44 e 45, os percentuais de alçamento por série, tendo em vista os fatores que as compõem.

Relativos à faixa etária e ao sexo dos entrevistados, os resultados apresentados nas Tabelas 42 e 43 revelam comportamentos singulares. Todos os percentuais indicam a maior incidência da manutenção nas amostras, mas, se, em /e/, informantes do sexo masculino $(37.5 \%)$ e da faixa intermediária alçam mais (40.5\%); em /o/, a elevação é recorrente no sexo feminino (45\%) e em pessoas mais velhas $(44.5 \%)$.

Tabela 42 Atuação da variável Faixa etária dos informantes para o alçamento de /e/ e de /o/, no PST

\begin{tabular}{|l|c|c|c|c|}
\hline \multirow{2}{*}{\multicolumn{1}{c|}{ VARIÁVEL FAIXA ETÁRIA }} & \multicolumn{2}{c|}{ [I] } & \multicolumn{2}{c|}{ [u] } \\
\cline { 2 - 5 } & 0co. & $\%$ & 0co. & $\%$ \\
\hline $25-35$ anos & $502 / 1.359$ & 37 & $422 / 1.001$ & 42 \\
\hline $36-55$ anos & $446 / 1.107$ & $\mathbf{4 0 . 5}$ & $364 / 884$ & 41 \\
\hline 56 em diante & $268 / 868$ & 31 & $358 / 804$ & $\mathbf{4 4 . 5}$ \\
\hline
\end{tabular}

Tabela 43 Atuação da variável Sexo dos informantes para o alçamento de /e/ e de /o/, no PST

\begin{tabular}{|l|c|c|c|c|}
\hline \multirow{2}{*}{ VARIÁVEL SEXO DOS INFORMANTES } & \multicolumn{2}{|c|}{$[\mathrm{l}]$} & \multicolumn{2}{c|}{ [u] } \\
\cline { 2 - 5 } & Oco. & $\%$ & 0c0. & $\%$ \\
\hline Masculino & $805 / 2.144$ & $\mathbf{3 7 . 5}$ & $660 / 1.620$ & 41 \\
\hline Feminino & $411 / 1.190$ & 34.5 & $484 / 1.073$ & $\mathbf{4 5}$ \\
\hline
\end{tabular}


A Tabela 44 contrasta os índices percentuais e de ocorrências encontrados para a variável Frequência de uso do Forro nas duas séries:

Tabela 44 Atuação da variável Frequência de uso do Forro para o alçamento de /e/ e de /o/, no PST

\begin{tabular}{|l|c|c|c|c|}
\hline \multirow{2}{*}{ VARIÁVEL FREQUÊNCIA DE USO DO FORRO } & \multicolumn{2}{|c|}{ [i] } & \multicolumn{2}{c|}{ [u] } \\
\cline { 2 - 5 } & OCO. & $\%$ & oco. & $\%$ \\
\hline Pouca ou nenhuma & $590 / 1.536$ & $\mathbf{3 8 . 5}$ & $613 / 1.254$ & $\mathbf{4 9}$ \\
\hline Média & $572 / 1.559$ & 36.5 & $472 / 1.222$ & 38.5 \\
\hline Alta & $54 / 239$ & 22.5 & $59 / 217$ & 27 \\
\hline
\end{tabular}

Nos dois casos, quanto menor o contato com o Forro, maiores os percentuais de elevação, sugerindo alguma relação entre a língua oficial (o Português) e a manifestação do processo.

Por fim, de acordo com a Tabela 45, o número total de ocorrências e os percentuais das pronúncias [i] e [u] são diretamente proporcionais à formação dos entrevistados, sendo mais frequentes quanto mais elevado é o grau de escolaridade.

Tabela 45 Atuação da variável Escolaridade dos informantes para o alçamento de /e/ e de /o/, no PST

\begin{tabular}{|l|c|c|c|c|}
\hline \multirow{2}{*}{$\begin{array}{c}\text { VARIÁVEL ESCOLARIDADE } \\
\text { DOS INFORMANTES }\end{array}$} & \multicolumn{2}{|c|}{ [i] } & \multicolumn{2}{c|}{ [u] } \\
\cline { 2 - 5 } & oco. & $\%$ & 0co. & $\%$ \\
\hline Fundamental - 5 a 8 anos de escolaridade & $252 / 818$ & 31 & $277 / 754$ & 36.5 \\
\hline Médio - 9 a 11 anos de escolaridade & $405 / 1.212$ & 33.5 & $330 / 887$ & 37 \\
\hline $\begin{array}{l}\text { Superior - mais de 11 anos de } \\
\text { escolaridade }\end{array}$ & $\mathbf{5 5 9 / 1 . 3 0 4}$ & $\mathbf{4 3}$ & $537 / 1.052$ & $\mathbf{5 1}$ \\
\hline
\end{tabular}

Ao longo deste capítulo, sempre que possível, compararam-se os comportamentos das vogais médias pretônicas em diferentes variedades do Português, com base em dados contemporâneos de Nova Iguaçu (ROCHA, 2013) e do PST. Naquela investigação, a variável escolaridade foi selecionada apenas na série posterior, mas divulgam-se os índices percentuais e de ocorrências em uma das etapas do estudo. A fim de relacionar, mais uma vez, tais realidades linguísticas, a Tabela 46 retoma os resultados expostos em Rocha (2013: 137) e indica que a elevação 
na fala de Nova Iguaçu varia em função da série analisada. Com índices muito baixos e próximos entre si, em /e/, o maior percentual de alçamento coincide com o nível superior de escolaridade. Já, em /o/, o oposto se verifica, uma vez que os percentuais decrescem à medida que a escolaridade aumenta.

Tabela 46 Atuação da variável Escolaridade dos informantes para o alçamento de /e/ e de /o/, na fala de Nova Iguaçu (cf. ROCHA, 2013: 137)

\begin{tabular}{|l|c|c|c|c|}
\hline \multirow{2}{*}{$\begin{array}{c}\text { VARIÁVEL ESCOLARIDADE } \\
\text { DOS INFORMANTES }\end{array}$} & \multicolumn{2}{c|}{ [i] } & \multicolumn{2}{c|}{ [u] } \\
\cline { 2 - 5 } & oco. & $\%$ & 0co. & $\%$ \\
\hline Ensino Fundamental & $307 / 2.003$ & 15 & $356 / 1.430$ & $\mathbf{2 5}$ \\
\hline Ensino Médio & $282 / 1.941$ & 14.5 & $225 / 1.148$ & 20 \\
\hline Ensino Superior & $357 / 2.269$ & $\mathbf{1 6}$ & $293 / 1.670$ & 17 \\
\hline
\end{tabular}

Associadas às evidências do PE descritas na seção 2.1, as semelhanças constatadas permitem que se insira o PST em um continuum afrobrasileiro. Em um extremo cujas normas são a elevação e a redução vocálicas se inseriria o Português Europeu, noutro em que a manutenção é a preferência, em meio a casos de alteamento, se situaria o Português do Brasil e, entre ambos, mas mais próximo da realidade brasileira, parece estar localizada a variedade urbana do Português de São Tomé.

Quadro 6 Esboço de um continuum do alteamento de /e/ e de /o/ nas variedades brasileira, europeia e santomense da língua portuguesa

\begin{tabular}{|c|c|c|c|}
\hline \multicolumn{3}{|c|}{ [+ alteamento] } & [-alteamento] \\
\hline \multicolumn{4}{|c|}{ 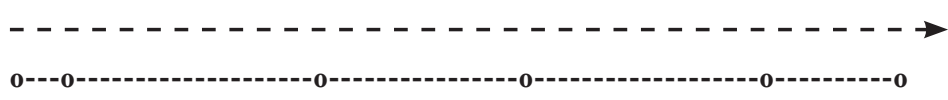 } \\
\hline [i] PE & & $\begin{array}{l}\text { PST }(F)=31 \% \\
\text { PST }(M)=33,5 \\
\text { PST (S) }=43 \%\end{array}$ & $\begin{array}{l}P B(F)-15 \% \\
P B(M)=14,5 \% \\
P B(S)=16 \%\end{array}$ \\
\hline [u] PE & $\operatorname{PST}(S)=51 \%$ & $\begin{array}{l}\text { PST }(F)=36,5 \% \\
\text { PST }(M)=37 \%\end{array}$ & $\begin{array}{l}P B(F)=25 \% \\
P B(M)=20 \% \\
P B(S)=17 \%\end{array}$ \\
\hline
\end{tabular}

Legenda - Niveis de escolaridade: $(F)$ = Fundamental $/(M)$ = Médio $/(S)$ = Superior

Variedades do Português: PE: Português Europeu/ PB: Português do Brasil/ PST: Português de São Tomé 


\section{REFERÊNCIAS}

ARAUJO, G. A. Empréstimos recentes do Português, variação fonética e a sílaba na língua são-tomense da ilha de São Tomé. Papia, São Paulo, v. 17, p. 55-66, 2007.

BISOL, L. A. Harmonia vocálica: uma regra variável. 1981. Tese (Doutorado em Linguística) - Faculdade de Letras, Universidade Federal do Rio de Janeiro, Rio de Janeiro, 1981.

BISOL, L. A neutralização das átonas. Revista DELTA, São Paulo, v. 19, n .2, p. $267-$ 276, 2003.

BORTONI, S. M.; GOMES, C. A.; MALVAR, E. da S. 1992. A variação das vogais médias pretônicas no Português de Brasília: um fenômeno neogramático ou de difusão lexical? Revista de Estudos da Linguagem, Belo Horizonte, UFMG, ano 1, v. 1, p. 9-29, 1992.

BRANDÃO, S. F.; ROCHA, F. M. V.; SANTOS, E. R. Vogais médias pretônicas em início de vocábulo na fala do Rio de Janeiro. Letras \& Letras: estudos em fonologia, Uberlândia: EDUFU, v. 28, p. 244-257, 2012. 182.

CALLOU, D.; LEITE, Y. Iniciação à fonética e à fonologia. Rio de Janeiro: Jorge Zahar, 2005.

CÂMARA JR., J. M. Estrutura da lingua portuguesa. Rio de Janeiro: Vozes, 1970.

CÂMARA JR., J. M. Para o estudo da fonêmica portuguesa. Rio de Janeiro: Padrão, 1977.

CARMO, M. N. As vogais médias pretônicas dos verbos na fala culta do interior paulista. 2009. Dissertação (Mestrado em Linguística) - Faculdade de Letras, Universidade Estadual Paulista, São Paulo, 2009.

FERRAZ, L. I. The creole of São Tomé. Johanesburgo: Witwatersrand University Press, 1979.

FERRAZ, L. I. Portuguese creoles of West Africa and Asia. In: GILBERT, G. G. (Ed.). Pidgin and creole languages: essays in memory of John E. Reinecke. Honolulu: University of Hawai Press, 1987. p. 337-360.

GONÇALVES, R. M. G. Propriedades de subcategorização verbal no Português de São Tomé. 2010. Dissertação (Mestrado em Linguística) - Faculdade de Letras, Universidade de Lisboa, Lisboa, 2010.

GONÇALVES, R. M. G.; HAGEMEIJER, T. O Português num contexto multilingue: O caso de São Tomé e Príncipe. Revista Científica da Universidade Eduardo Mondlane, Moçambique, v. 1, n. 1, p. 87-107, 2015.

HAGEMEIJER, T. Clause structure in Santomé. 2007. Tese (Doutorado em Linguística) - Faculdade de Letras, Universidade de Lisboa, Lisboa, 2007.

HAGEMEIJER, T. Initial vowel agglutination in the Gulf of Guinea creoles. In: ABOL, E.; SMITH, N. (Eds.). Complex processes in new languages. Amsterdam/Filadélfia: John Benjamins Publishing Company, 2009 c. p. 29-50. 
HAGEMEIJER, T. comparação sintáctica. Papia, São Paulo, v. 22, n. 2, p. 233-251, 2012.

MATEUS, M. H. M.; D’ANDRADE, E. The phonology of portuguese. Oxford: Oxford University Press, 2000.

MOTA, J. A.; CARDOSO, S. A. M. Para uma nova divisão dos estudos dialetais brasileiros. In: MOTA, J. A.; CARDOSO, S. A. M. (Eds.). Documentos 2: Projeto Atlas Linguístico do Brasil. Salvador: Quarteto, 2006. p. 15-34.

NASCENTES, A. O linguajar carioca. 2. ed. Rio de Janeiro: Organização Simões, 1953 [1922].

NASCIMENTO, Fabiane de Mello Vianna da Rocha Teixeira Rodrigues do. O sistema vocálico do Português de São Tomé e o comportamento das vogais médias em contexto pretônico. Tese (Doutorado em Letras Vernáculas/Língua Portuguesa) - Faculdade de Letras, Universidade Federal do Rio de Janeiro, Rio de Janeiro, 2018.

ROCHA, Fabiane de Mello Vianna. da. O comportamento das vogais médias pretônicas na fala de Nova Iguaçu. Dissertação (Mestrado em Letras Vernáculas/Língua Portuguesa) - Faculdade de Letras, Universidade Federal do Rio de Janeiro, Rio de Janeiro, 2013.

SILVEIRA, A. C. Ditongos no Português de São Tomé e Príncipe. Dissertação (Mestrado em Filologia e Língua Portuguesa) - Faculdade de Letras, Universidade de São Paulo, São Paulo, 2013. 
